Prepared in cooperation with U.S. Army Corps of Engineers

\title{
Vulnerability of Larval Lamprey to Columbia River Hydropower System Operations-Effects of Dewatering on Larval Lamprey Movements and Survival
}

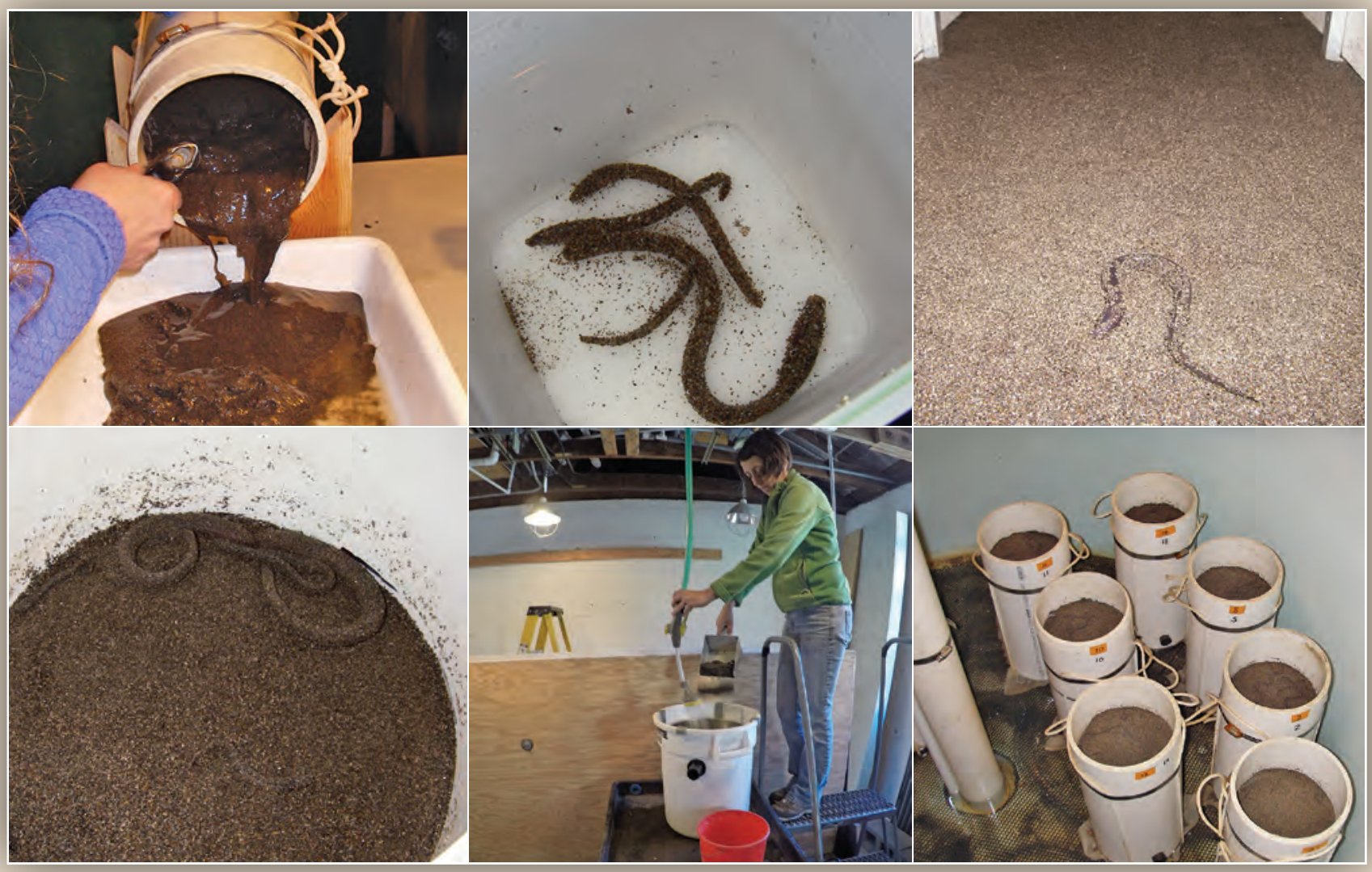

Open-File Report 2015-1157 
Cover:

Top Left: Collecting larval lamprey from PVC tube following a survival trial.

Top Middle: Larval lamprey in water immediately following the completion of a dewatering exposure in a survival trial.

Top Right: Larval lamprey moving downslope in the movement trial test tank.

Bottom Left: Lamprey on the surface of the sand used to fill PVC tubes during survival trials.

Bottom Middle: Separating sand and lamprey removed from the movement trial test tank.

Bottom Right: PVC tubes in a tank during a dewatering survival trial.

All photographs were taken by Lisa Weiland, U.S. Geological Survey, except for bottom middle photograph, which was taken by Lisa Gee, U.S. Geological Survey. 


\section{Vulnerability of Larval Lamprey to Columbia River Hydropower System Operations-Effects of Dewatering on Larval Lamprey Movements and Survival}

By Theresa L. Liedtke, Lisa K. Weiland, and Matthew G. Mesa

Prepared in cooperation with U.S. Army Corps of Engineers

Open-File Report 2015-1157

U.S. Department of the Interior

U.S. Geological Survey 


\section{U.S. Department of the Interior \\ SALLY JEWELL, Secretary}

\section{U.S. Geological Survey \\ Suzette M. Kimball, Acting Director}

U.S. Geological Survey, Reston, Virginia: 2015

For more information on the USGS—-the Federal source for science about the Earth, its natural and living resources, natural hazards, and the environment-visit http://www.usgs.gov/ or call 1-888-ASK-USGS (1-888-275-8747).

For an overview of USGS information products, including maps, imagery, and publications, visit http://www.usgs.gov/pubprod/.

Any use of trade, firm, or product names is for descriptive purposes only and does not imply endorsement by the U.S. Government.

Although this information product, for the most part, is in the public domain, it also may contain copyrighted materials as noted in the text. Permission to reproduce copyrighted items must be secured from the copyright owner.

Suggested citation:

Liedtke, T.L., Weiland, L.K., and Mesa, M.G., 2015, Vulnerability of larval lamprey to Columbia River hydropower system operations-Effects of dewatering on larval lamprey movements and survival: U.S. Geological Survey Open-File Report 2015-1157, 28 p., http://dx.doi.org/10.3133/ofr20151157.

ISSN 2331-1258 (online) 


\section{Contents}

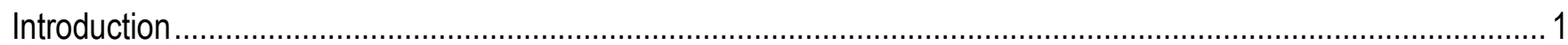

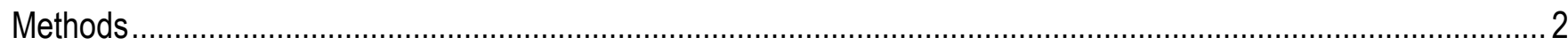

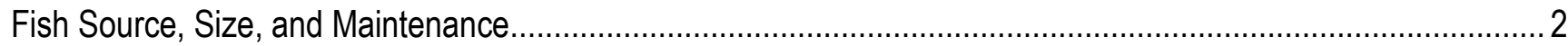

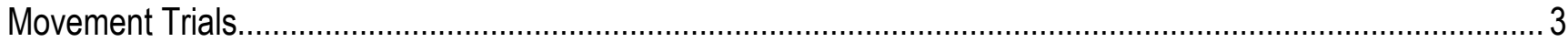

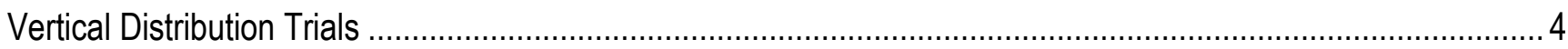

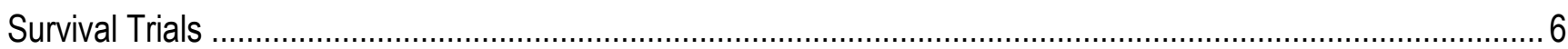

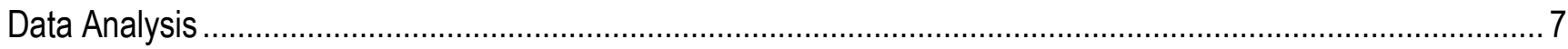

Results.

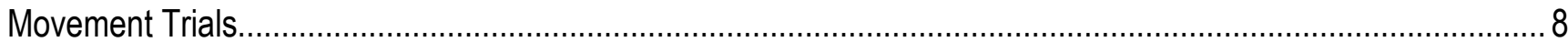

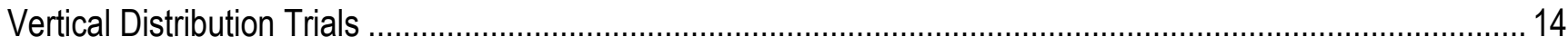

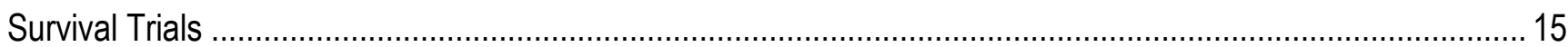

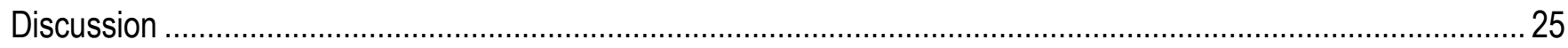

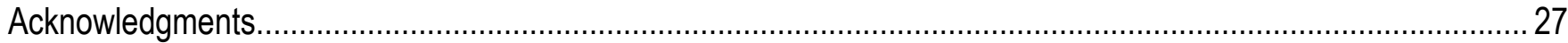

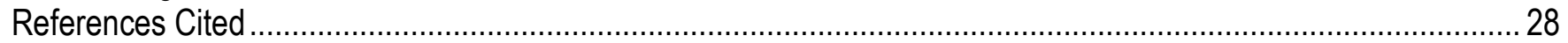

\section{Figures}

Figure 1. Schematic of the tank constructed to evaluate lamprey movements in response to dewatering................ 4

Figure 2. Photographs of the plastic tubes used for tests of ammocoete vertical distribution ................................. 5

Figure 3. Graph showing percentage of fish (bars) and mean total length (points \pm SE bars) of fish in each tank section for three dewatering levels tested at the slow (7.6 centimeters per hour) dewatering rate .................. 10

Figure 4. Graph showing percentage of fish (bars) and mean total length (points \pm SE bars) of fish in each tank section for three dewatering levels tested at the fast (51 centimeters per hour) dewatering rate.................... 10

Figure 5. Graph showing percentage of fish recovered in each tank section following dewatering at the

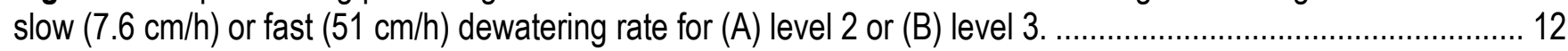

Figure 6. Graph showing mean total length of ammocoetes ( \pm SE bars) recovered in tank section 1 , stranded in middle tank sections, or watered tanks sections or section 7 for two dewatering rates and two dewatering levels.

Figure 7. Graph showing mean total length of ammocoetes ( \pm SE bars) used in the control and treatment (dewatered) groups for three trials evaluating the survival of fish following dewatering.....

Figure 8. Graph showing mean percent soil moisture ( \pm SE bars) in sample tubes dewatered for a series of exposure times and three trials.

Figure 9. Graph showing percent mortality for larval lamprey exposed to dewatered conditions for a series of exposure times and for three experimental trials

Figure 10. Graph showing mean number of fish on the surface of sample tubes for the first 8 hours of exposure to dewatered conditions for three experimental trials

Figure 11. Graph showing mean total length of ammocoetes (+ SE bars) used in three experimental trials for a range of exposure times

Figure 12. Graphs showing predicted probability of mortality for a 48-hour exposure to dewatered conditions based on total length of fish, whether they were on the surface of the sediment (surface) or burrowed in the sediment (burrowed) for each of three experimental trials 


\section{Tables}

Table 1. Total lengths and weights of three size classes of ammocoetes used in three experimental trials to evaluate the effects of dewatering on larval lamprey movement and survival

Table 2. Variables used in logistic regression models for analysis of larval lamprey survival following dewatering .. 7 Table 3. Summary of dewatering movement trials, including dewatering rate, dewatering level, number of trials, trial dates, mean water temperature, number of fish, and mean total length

Table 4. Number and percentage of fish outside tank section 1, and fish classified as stranded and non-stranded for two dewatering rates and two dewatering levels

Table 5. Number and percentages of larval lamprey in 1- or 4-hour exposures to control (submerged) and test (dewatered) conditions in three depth strata

Table 6. Number, mean total length, and standard deviation of larval lamprey in 1- or 4-hour exposures to control (submerged) and test (dewatered) conditions in three depth strata.

Table 7. Trial number, trial date, air temperature, humidity, and dew point for three dewatering survival trials...... 17

Table 8. Soil moisture content for the surface and bottom of sample tubes in three dewatering survival trials....... 17 Table 9. Descriptive statistics for the final logistic regression model selected to represent the survival of larval lamprey following exposure to dewatering conditions.

Table 10. Odds ratios for effects modeled for the probability of death in the final logistic regression model selected to represent the survival of larval lamprey following exposure to dewatered conditions.

Table 11. Odds ratios for effects modeled for the probability of survival in the final logistic regression model selected to represent the survival of larval lamprey following exposure to dewatered conditions.

Table 12. Number, percent, mean total length, standard deviation and range of ammocoetes on the surface and burrowed into the sediment at the time of sampling for dewatering survival trials.

Table 13. Summary of the number and percent of lamprey on the surface or burrowed into the sediment for three dewatering trials and seven exposure times.

\section{Conversion Factors}

International System of Units to Inch/Pound to

\begin{tabular}{|c|c|c|}
\hline Multiply & By & To obtain \\
\hline \multicolumn{3}{|c|}{ Length } \\
\hline millimeter (mm.) & 0.03937 & inch (in.) \\
\hline centimeter $(\mathrm{cm})$ & 0.3937 & inch (in.) \\
\hline meter $(\mathrm{m})$ & 3.281 & foot $(\mathrm{ft})$ \\
\hline \multicolumn{3}{|c|}{ Volume } \\
\hline liter $(\mathrm{L})$ & 0.2642 & gallon (gal) \\
\hline \multicolumn{3}{|c|}{ Mass } \\
\hline milligram (mg) & 0.00003527 & ounce, avoirdupois (oz) \\
\hline $\operatorname{gram}(\mathrm{g})$ & 0.03527 & ounce, avoirdupois (oz) \\
\hline
\end{tabular}

Temperature in degrees Celsius $\left({ }^{\circ} \mathrm{C}\right)$ may be converted to degrees Fahrenheit $\left({ }^{\circ} \mathrm{F}\right)$ as ${ }^{\circ} \mathrm{F}=\left(1.8 \times{ }^{\circ} \mathrm{C}\right)+32$.

\section{Supplemental Information}

Concentrations of chemical constituents in water are given in milligrams per liter (mg/L). 


\title{
Vulnerability of Larval Lamprey to Columbia River Hydropower System Operations-Effects of Dewatering on Larval Lamprey Movements and Survival
}

\author{
By Theresa L. Liedtke, Lisa K. Weiland, and Matthew G. Mesa
}

\section{Introduction}

Numbers of adult and juvenile Pacific lamprey (Entosphenus tridentatus) in the upper Columbia River Basin of the interior Pacific Northwest have decreased from historical levels (Close and others, 2002), raising concerns from State and Federal agencies and Tribal entities. In 1994, the U.S. Fish and Wildlife Service designated Pacific lamprey as a Category 2 candidate species and in 2003, the species was petitioned for listing under the Endangered Species Act. Listing consideration and potential recovery planning are significantly hindered by a lack of information on the basic biology and ecology of lampreys, including limiting factors. To date (2015), several factors that may limit lamprey production require study, including dam passage issues, contaminants, and effects on habitat.

Lampreys have a complex life history, and studies evaluating their biology, ecology, and limiting factors are important to effectively manage, protect, and restore these unique fish. One phase of their life history - the larval (ammocoete) phase - has received very little study in main stem Columbia River reservoirs. This is a critical research need because sediments in these reservoirs likely contain a high proportion of larval habitat, and ammocoetes live for several years burrowed in sediments, where they are filter feeders on detritus and organic matter. Larval Pacific lampreys and Lampetra species have recently been discovered in sediments of the Willamette River (Jolley and others, 2012), as well as the main stem Columbia River, including reservoirs created by hydroelectric dams (Jolley and others, 2014). The highest abundance of larvae was present in the sediments of tributary deltas where habitat was available in the form of large sand deposits and mud flats.

Ammocoetes are vulnerable to water-management operations of hydroelectric dams on the Columbia River. Water levels in the reservoirs created by dams often fluctuate based on the needs to generate power, to spill water to pass fish, to aid navigation, and other factors. Reservoir drawdowns at various levels are common, and occur more often and at faster rates than elevation changes in unregulated systems. For example, the mean hourly rate of drawdown and daily change in elevation for the Bonneville Reservoir are more than four times greater than those for the undammed Fraser River in Canada (U.S. Geological Survey, unpub. data, 2015). Ammocoetes living in the sediments of tributary deltas in the Columbia River are likely to have their habitat dewatered when the reservoir elevation is reduced, and it is not known whether they can effectively move to deeper water or survive for periods when little to no water is available. There is a critical need for this information because ammocoetes are known to be present in tributary delta areas that are vulnerable during drawdowns, and larvae were present in a broad range of sizes, indicating multiple age classes and long-term rearing (Jolley and others, 2012, 2013). Information on the response of lamprey to dewatering also would be useful in other settings, such as when sediments are dewatered for culvert installation and irrigation diversions. 
This study evaluated the effects of dewatering on larval lamprey movement and survival. To the best of our knowledge, this topic has not been addressed before. The study was funded by the U.S. Army Corps of Engineers as part of a larger effort to better understand where these young fish are found in the Columbia River (Jolley and others, 2012, 2013), and what reservoir areas may be dewatered under a series of dam operating scenarios (Mueller and others, 2014). The objective of this controlled laboratory study was to document the response of larval lamprey to dewatering of their habitat, specifically - (1) their movements relative to fish size and ramping rates, and (2) their survival relative to fish size and duration of exposure.

\section{Methods}

\section{Fish Source, Size, and Maintenance}

Lamprey ammocoetes were collected using electrofishing and sediment grab samples from Gibbons Creek, Washington, and Herman Creek, Oregon, in 2010, 2012, and 2013. Fish also were obtained from the Yakima Nation Prosser Fish Hatchery in Prosser, Washington, in 2014 that were originally salvaged from diversions in the Yakima Basin. Ammocoetes were presumed to be Pacific lamprey, although Western brook lamprey (Lampetra richardsoni) also reside in similar habitat and are difficult to distinguish from Pacific lamprey ammocoetes when fish are small $(<60 \mathrm{~mm}$ total length [TL]). We did not verify their identity. To reduce the effect on local fish populations, we also spawned adult Pacific lamprey in our laboratory in June 2012 and 2013, and reared the offspring using protocols adapted from Meeuwig and others (2005). Laboratory-spawned Pacific lamprey and wild ammocoetes were held in rectangular fiberglass tanks $(51 \times 43 \times 27 \mathrm{~cm})$. Each tank contained beach sand for burrowing substrate at a depth of about $5 \mathrm{~cm}$ for wild ammocoetes and $2.5 \mathrm{~cm}$ for laboratory-spawned ammocoetes. More sediment was provided for the wild ammocoetes, as they were larger than the laboratory-spawned ammocoetes. The sand used for culture and all experiments had a median grain size of $0.378 \mathrm{~mm}$. Tanks were illuminated with a simulated natural photoperiod using overhead incandescent lights and were supplied with sand-filtered water $(1.5 \mathrm{~L} / \mathrm{min})$ from the Little White Salmon River, Washington. Fish were fed a slurry of active yeast and commercial fry food (Gemma Wean 0.1; Skretting, Vancouver, British Columbia) using methods modified from Rose and Mesa (2012). Water temperatures during normal rearing ranged from 7.2 to $10.0^{\circ} \mathrm{C}$.

The different collection and culture efforts over several years yielded three general size classes of ammocoetes - fish less than $56 \mathrm{~mm}, 56-95 \mathrm{~mm}$, and greater than $95 \mathrm{~mm}$ TL (table 1). For all experiments, ammocoetes were selected from each size class in approximately equal numbers to include the full range of sizes available. Individual fish were not reused for multiple experiments, so all trials used non-exposed or naïve fish.

Table 1. Total lengths and weights of three size classes of ammocoetes used in three experimental trials to evaluate the effects of dewatering on larval lamprey movement and survival.

[Abbreviations: TL, total length; mm, millimeter; SD, standard deviation; Min, minimum; max, maximum; g, gram]

\begin{tabular}{llrccc}
\hline Size class & \multicolumn{1}{c}{ TL range } & $\begin{array}{c}\text { Mean TL } \\
(\mathbf{m m})(\mathbf{S D})\end{array}$ & $\begin{array}{c}\text { Min, } \max \text { TL } \\
(\mathbf{m m})\end{array}$ & $\begin{array}{c}\text { Mean weight } \\
(\mathbf{g})(\mathbf{S D})\end{array}$ & $\begin{array}{c}\text { Min, max weight } \\
(\mathbf{g})\end{array}$ \\
\hline Small & Less than $56 \mathrm{~mm}$ & $44(4.3)$ & 31,55 & $0.2(0.1)$ & $0.01,0.5$ \\
Medium & 56-95 $\mathrm{mm}$ & $75(11.2)$ & 56,95 & $0.7(0.3)$ & $0.2,1.3$ \\
Large & More than $95 \mathrm{~mm}$ & $120(11.2)$ & 96,148 & $2.5(0.7)$ & $1.2,4.9$ \\
\hline
\end{tabular}




\section{Movement Trials}

To test ammocoete movements in response to dewatering, we built a wooden tank $(239 \times 30 \times 122$ $\mathrm{cm})$ with a false bottom at a 10 -percent slope $\left(5.71^{\circ}\right)$ and coated it with epoxy paint (fig. 1). A drain was placed at one end with a perforated divider positioned $29 \mathrm{~cm}$ from the end to hold the substrate in place, but allow the tank to drain water. The tank was filled to a depth of $30.5 \mathrm{~cm}$ with sand, maintaining the 10 percent slope. The tank was portioned into seven sections. Metal dividers were used to partition the first four sections and lines on the tank walls divided the last three sections (fig. 1). Sections $1-6$ were $30.5 \mathrm{~cm}$ long, and section 7 was $27 \mathrm{~cm}$ long. The tank received heated river water $(3 \mathrm{~L} / \mathrm{min})$ that ranged from 8.9 to $10.8^{\circ} \mathrm{C}$.

Two dewatering rates and three dewatering levels were tested. The two dewatering rates were based on water-elevation data from the U.S. Geological Survey near Stevenson, Washington (http://waterdata.usgs.gov/nwis). The slow dewatering rate $(7.6 \mathrm{~cm} / \mathrm{h})$ is similar to the undammed lower Fraser River in British Columbia, Canada (https://wateroffice.ec.gc.ca), and the fast dewatering rate (51 $\mathrm{cm} / \mathrm{h}$ ) represents a drawdown scenario typical of regulated river systems. The three dewatering levels we tested resulted in successively increasing amounts of dewatered substrate in the sloped experimental tank. Dewatering level 1 was at the highest substrate level, level 2 was $15.2 \mathrm{~cm}$ below level 1, and level 3 was $30.5 \mathrm{~cm}$ below level 1 (fig. 1). All tank sections were submerged at dewatering level 1. At level 2, the lower part of section 5 and all sections 6 and 7 had water over the sand substrate. At level 3, none of the tank sections had water over the surface of the sand (fig. 1). We completed three trials of each rate and dewatering level combination using 10 lamprey per trial. Additionally, three control trials were completed where the tank was not dewatered. All trials used a $4 \mathrm{~h}$ wait period after trial conditions were established in the tank, after which fish were located and removed. Trials were conducted during daylight hours, following an overnight acclimation period.

The afternoon before a trial, the water level in the tank was set to about $15 \mathrm{~cm}$ above the highest substrate level to accommodate the stocking of test fish. A metal divider was pushed into the substrate to the bottom of the tank at the lower border of section 1 to prevent fish from moving out of section 1 . Ten fish (3-4 fish from each size class) were randomly selected and placed in section 1 . After all fish burrowed into the substrate, the inflow water was turned on to fill the tank and the fish were allowed to acclimate in section 1 overnight. The following morning, the inflow water was turned off, the drain pipe and the section 1 metal divider were removed, and the drain valve was set to the slow or the fast drawdown rate. The tank was checked hourly and adjustments were made as necessary to maintain the drawdown rate. Once the target dewatering level was reached, the drain valve was closed and the 4-h waiting period began. During the waiting period for dewatering level 1, the tank was checked every 30 min to record fish movements on the substrate surface and their subsequent burrowing positions. When the substrate was exposed during dewatering levels 2 and 3, ammocoete movements were closely monitored (at least every $15 \mathrm{~min}$ ). At the completion of the trial, the metal dividers were pushed into the substrate and the tank was drained. Fish on the surface were recorded and removed. To locate burrowed fish, sand was removed with a scoop, placed on a sieve over a large tub, and gently sprayed with water. Sand removal continued until all 10 fish were recovered. Fish were anesthetized in a solution of tricaine methanesulfonate $(100 \mathrm{mg} / \mathrm{L})$, buffered with an equal amount of sodium bicarbonate, to facilitate collection of weight and length data. Control trials followed the same procedures, except that the tank was not dewatered and the waiting period began as soon as the inflow was turned off and the divider for section 1 was removed. 


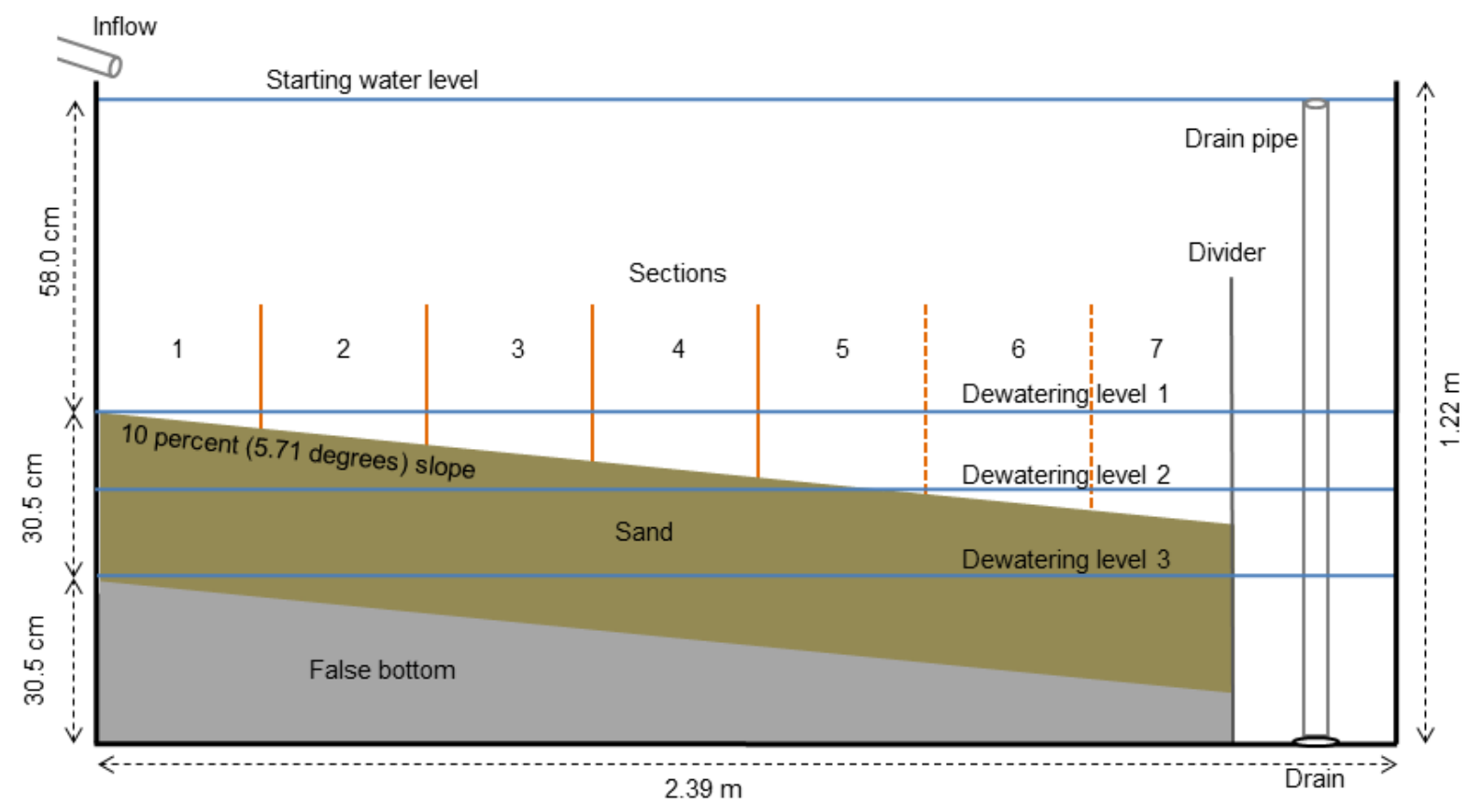

Figure 1. Schematic of the tank constructed to evaluate lamprey movements in response to dewatering. The tank was sloped at a 10-percent grade, filled with sand, and divided into seven tank sections. Metal dividers (solid orange vertical lines) were used to partition the first four sections and lines on the tank walls (dashed orange vertical lines) divided the last three sections. The elevations of the three test dewatering levels are shown by horizontal blue lines.

\section{Vertical Distribution Trials}

The vertical distribution of lamprey during watered and dewatered conditions was tested in order to design an effective experimental system for the survival trials. Specifically, the maximum burrowing depth needed to be determined to establish the appropriate length for the experimental enclosures. Our objectives for these trials were to determine how deep in the sediments ammocoetes would burrow, and if their vertical distribution was different between 1- and 4-h exposures to dewatering conditions. We constructed three 15.2-cm-diameter plastic tubes, $38.1 \mathrm{~cm}$ high, and partitioned each of them into four sections. The three lower sections were $7.6 \mathrm{~cm}$ tall, and the top section was $15.2 \mathrm{~cm}$ tall. The bottom tube sections were covered with nylon bolt cloth (aperture of $425 \mu \mathrm{m}$ ) to allow water to drain. The four tube sections were stacked, secured in a column using neoprene sleeves, and filled with $30.5 \mathrm{~cm}$ of sand (fig. 2). The top tube section had $7.6 \mathrm{~cm}$ of sand and $7.6 \mathrm{~cm}$ of unfilled space to allow the fish access to the surface of the substrate. 

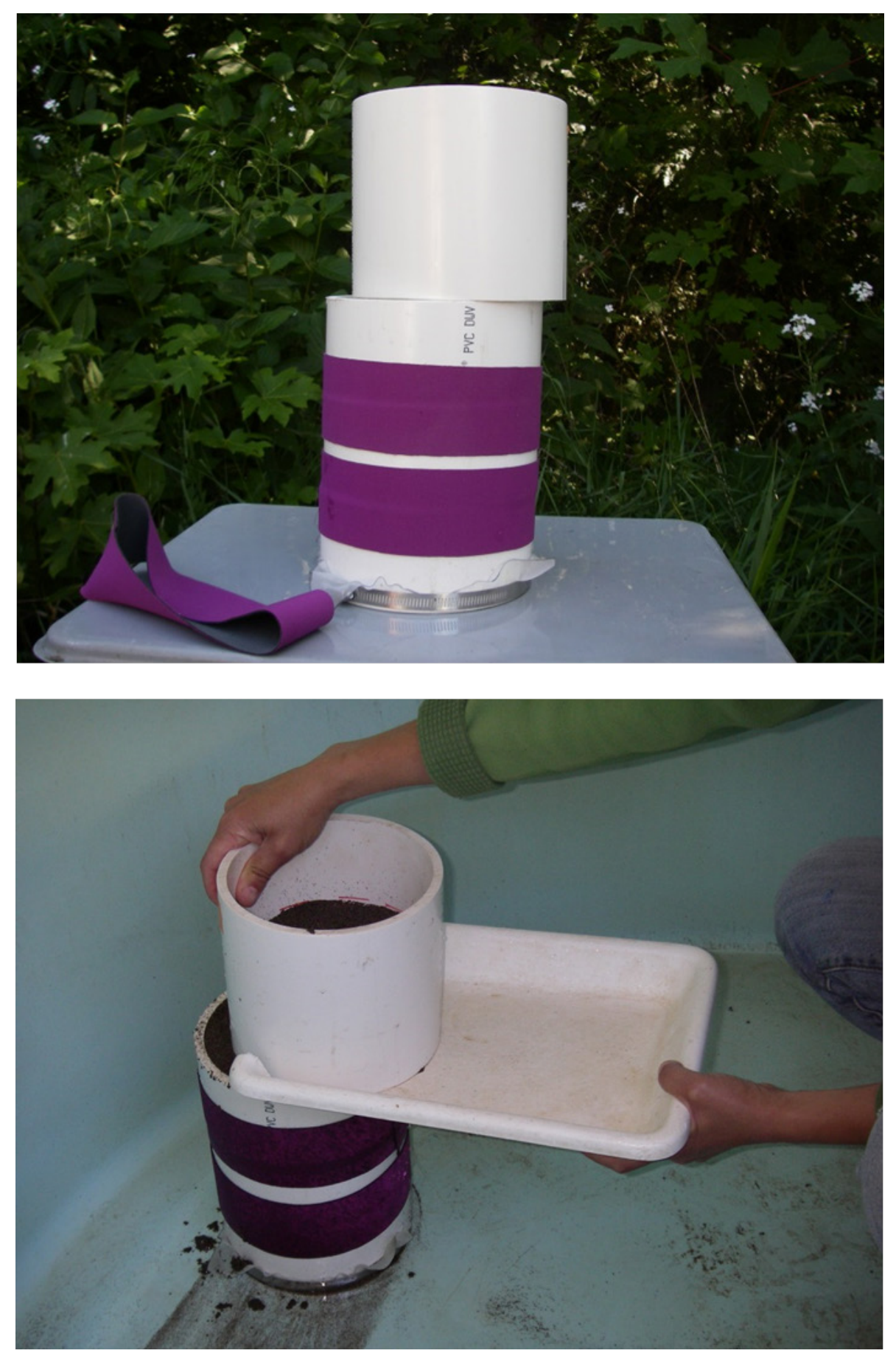

Figure 2. Photographs of the plastic tubes used for tests of ammocoete vertical distribution. The top image shows the tube sections held in place with neoprene sleeves, and the bottom image shows the removal of the top section into a tray. Photograph by Lisa Gee, U.S. Geological Survey, June 9, 2015. 
To begin a trial, two tubes were placed on the bottom of a 1.52-m-diameter fiberglass tank, and the tank was filled to just above the sand surface in the tubes. A control tube was placed in a second, similar tank and filled to the same level. Tank water temperatures during the trials ranged from 7.1 to $9.1^{\circ} \mathrm{C}$. Eight lamprey (2-3 from each size class) were randomly selected and placed in each of the treatment tubes. The control tube received six fish (two from each size class). The tops of the tubes were covered with mesh to prevent lamprey from leaving. When all fish had burrowed into the substrate, the water was turned on and the tanks were filled to a depth of $77.5 \mathrm{~cm}$. Fish were allowed to acclimate overnight. The following morning, the treatment tank inflow was turned off and a siphon was used to dewater the tank at a rate of $51 \mathrm{~cm} / \mathrm{h}$, similar to the movement trials. The exposure time of 1 or $4 \mathrm{~h}$ was initiated when the tank was fully drained. At the end of the 1 or $4 \mathrm{~h}$ exposure time, fish on the sand surface were removed and counted. The top neoprene sleeve was removed, and the top tube section was quickly slid onto an adjacent tray (fig. 2). The next two sections were removed in the same manner. Fish were removed from each tray, anesthetized, counted, weighed, and measured. The control tubes were processed using the same procedure, except that the tank was not dewatered.

\section{Survival Trials}

Three replicate survival trials were conducted using a time series of seven dewatered exposure periods - $0,4,8,12,24,36$, and $48 \mathrm{~h}$ - and were initiated during daylight hours. Sample tubes were the same dimensions as in the vertical distribution trials, except that they were not sectioned and a $2-\mathrm{cm}$ hole was drilled into each tube ( $5 \mathrm{~cm}$ from the bottom) and plugged with a rubber stopper to allow for sediment moisture sampling. For each trial, 21 treatment tubes were unsystematically placed on the bottom of a 1.52-m-diameter fiberglass tank and three control tubes were placed in an adjacent, equivalent tank. The tanks were filled with water until the level was just above the sand surface in the tubes to facilitate stocking of test fish. Three treatment tubes were randomly assigned to each of the seven exposure periods. Nine lampreys (three from each size class) were selected, anesthetized, weighed, measured, and placed in each of the treatment and control tubes. When all fish were stocked, the tops of the tubes were covered with mesh, the tanks were filled to a depth of $89 \mathrm{~cm}$, and fish were allowed to acclimate overnight. Water temperatures in the tanks ranged from 9.0 to $9.5{ }^{\circ} \mathrm{C}$.

Following overnight acclimation, the treatment tank inflow was turned off and the tank was drained with a siphon at a rate of $51 \mathrm{~cm} / \mathrm{h}$. The tank was fully drained in $1 \mathrm{~h} 45 \mathrm{~min}$. The $0 \mathrm{~h}$ sample was completed as soon as the tank was fully dewatered. We counted the number of lamprey on the surface of each tube hourly for the first $8 \mathrm{~h}$ after dewatering. At the completion of an exposure period, the three tubes pre-assigned to that exposure period were removed from the tank and air temperature and relative humidity were noted. To determine the moisture content of the sand, a sediment sample of about $20 \mathrm{~g}$ of sand was removed from the center of the tube at the surface and lower section ( $5 \mathrm{~cm}$ from bottom) of each tube. The rubber stopper on the tube was removed and a spatula was used to collect the bottom sample from near the center of the tube. The sediment samples were weighed to the nearest $0.001 \mathrm{~g}$, dried at $105{ }^{\circ} \mathrm{C}$ for at least $24 \mathrm{~h}$, and weighed again. Lamprey on the surface of the sand were gently removed and placed in holding containers with water. Fish disposition (active, lethargic, or dead) was recorded. To aid in the removal of fish burrowed in sand, tubes were placed horizontally on a sloped cradle and the contents of the tube were gently flushed into a collection tray. Fish were collected from the tray and placed in holding containers based on disposition. Holding containers had about $5 \mathrm{~cm}$ of sand, and they were placed in a large trough with flowing water for post-sampling observation. At 24-h post-sampling, each container was visually checked for fish disposition, and dead fish on the surface 
were removed and measured. At 48-h post-sampling, each container was emptied onto a sieve to aid with fish recovery. Fish were categorized by disposition, anesthetized, and measured. Control tubes were processed immediately after the 48-h exposure group. Although not exposed to dewatering, the control tubes had to be removed from the water in order to facilitate processing.

\section{Data Analysis}

For movement trials, we summarized the proportion of fish recovered in each tank section by dewatering rate and level. Similarly for vertical distribution trials, the number and proportion of fish were summarized by recovery location in the sample tube. Comparisons of fish size were made using Analysis of Variance (ANOVA) and Duncan's Multiple Range Test at a significance level of 0.05.

To describe the percentages and sizes of fish that moved out of section 1 during movement trails, we defined a stranding category for each dewatering level. Dewatering level 1 was excluded from these summaries because all tank sections were watered and there was no risk of stranding. For dewatering level 2, fish were categorized as stranded if they were recovered in tank sections 2,3 , or 4, and they were categorized as having found water if they were recovered in tank sections 5, 6, or 7. For dewatering level 3, fish were considered stranded in sections 2 through 6 . Fish in section 7 were not considered stranded (although the surface sand was dewatered) because they were in the position closest to water in the experimental system and would have had access to water in a natural system.

For survival trials, we coded fish condition as alive or dead and used the binary outcome as the response variable along with four predictor variables to run a series of logistic regression models. The predictor variables included trial, exposure period, fish position (on the surface and burrowed in the sand) and fish size (table 2). The exposure period was collapsed to fewer categories for the logistic regression analyses $(\leq 12,24,36$, and $48 \mathrm{~h})$. There were very few observed mortalities during the early exposure periods, and logistic regression does not perform well under these circumstances. To meet assumptions, the 0-, 4-, 8-, and 12-h exposure periods were combined and are presented as a single group, referred to as $\leq 12 \mathrm{~h}$. Comparisons of fish size and sediment moisture content were made using ANOVA and Duncan's Multiple Range Test at a significance level of 0.05. Dew-point temperature was calculated for each survival trial using the measured mean air temperature and mean relative humidity (Lawrence, 2005).

Table 2. Variables used in logistic regression models for analysis of larval lamprey survival following dewatering.

\begin{tabular}{|c|c|}
\hline Variable & Description \\
\hline Survival & $\begin{array}{l}\text { Response of larval lamprey exposed to dewatering conditions, recorded as "alive" or } \\
\text { "dead" at time of sampling. }\end{array}$ \\
\hline Exposure & $\begin{array}{l}\text { Amount of time lamprey were exposed to dewatered conditions. Sampling occurred at } 0 \text {, } \\
\quad 4,8,12,24,36 \text {, and } 48 \mathrm{~h} \text { following dewatering. }\end{array}$ \\
\hline Position & $\begin{array}{l}\text { At time of sampling, lamprey were noted to be on the "surface" of the substrate, or } \\
\text { "burrowed" in the substrate. }\end{array}$ \\
\hline Size & Total length (TL) of larval lamprey, in millimeters. \\
\hline Trial & $\begin{array}{l}\text { Three experimental trials were conducted }(1,2,3) \text { over time, with constant water } \\
\text { temperature and variable air temperatures and relative humidity. }\end{array}$ \\
\hline
\end{tabular}




\section{Results}

\section{Movement Trials}

We completed 21 dewatering movement trials between September 2014 and March 2015, using 209 ammocoetes (table 3). Water temperatures were similar across all trials and the mean TLs of ammocoetes used in the 21 trials were not significantly different $(\mathrm{F}=0.77, \mathrm{df}=20, p=0.75)$. The $7.6 \mathrm{~cm} / \mathrm{h}$ (slow) dewatering rate required several hours to reach the target dewatering levels - about $7 \mathrm{~h} 30 \mathrm{~min}$ for level 1; $9 \mathrm{~h} 20 \mathrm{~min}$ for level 2; and $10 \mathrm{~h} 40 \mathrm{~min}$ for level 3. The dewatering time was much less for the $51 \mathrm{~cm} / \mathrm{h}$ (fast) rate - about $1 \mathrm{~h} 10 \mathrm{~min}$ for level 1; $1 \mathrm{~h} 25 \mathrm{~min}$ for level 2; and $1 \mathrm{~h} 35 \mathrm{~min}$ for level 3. Some ammocoetes were injured during efforts to remove fish from the tank. Nine fish (4.3 percent) showed some sign of injury, likely due to either the metal dividers used to restrict fish movement or the scoop used to remove sand and fish from the tank. One fish was dead when lamprey were removed from the tank for processing during a fast rate trial. The fish showed no obvious injury and had a TL of $41 \mathrm{~mm}$.

Table 3. Summary of dewatering movement trials, including dewatering rate, dewatering level, number of trials, trial dates, mean water temperature, number of fish, and mean total length.

[See figure 1 for location of dewatering levels. Abbreviations: ${ }^{\circ} \mathrm{C}$, degrees Celsius; TL, total length; mm, millimeter; SD, standard deviation]

\begin{tabular}{|c|c|c|c|c|c|c|}
\hline $\begin{array}{l}\text { Dewatering } \\
\text { rate }\end{array}$ & $\begin{array}{l}\text { Dewatering } \\
\text { level }\end{array}$ & $\begin{array}{l}\text { Number } \\
\text { of trials }\end{array}$ & Trial dates & $\begin{array}{c}\text { Mean water } \\
\text { temperature } \\
\left({ }^{\circ} \mathrm{C}\right)\end{array}$ & $\begin{array}{l}\text { Number } \\
\text { of fish }\end{array}$ & $\begin{array}{l}\text { Mean TL } \\
(\mathrm{mm})(\mathrm{SD})\end{array}$ \\
\hline \multirow[t]{3}{*}{ Slow } & 1 & 3 & $\begin{array}{l}\text { October 27, 2014- February 2, } \\
2015\end{array}$ & $9.1-9.5$ & 30 & $80(26.8)$ \\
\hline & 2 & 3 & $\begin{array}{l}\text { December 17, 2014-March 17, } \\
2015\end{array}$ & $9.5-9.7$ & 29 & $83(31.0)$ \\
\hline & 3 & 3 & January 5-March 11, 2015 & $9.5-9.7$ & 30 & $86(34.2)$ \\
\hline \multirow[t]{3}{*}{ Fast } & 1 & 3 & September 8-30, 2014 & $9.0-9.4$ & 30 & $69(20.8)$ \\
\hline & 2 & 3 & $\begin{array}{l}\text { September 24-October 15, } \\
2014\end{array}$ & $9.1-9.4$ & 30 & $74(28.9)$ \\
\hline & 3 & 3 & September 23 October 8, 2014 & $9.2-9.6$ & 30 & $70(28.1)$ \\
\hline None & Control & 3 & January 26-February 18, 2015 & 9.5 & 30 & $85(33.0)$ \\
\hline
\end{tabular}


Some lamprey behaviors were similar across dewatering rates and levels. Although it was not rigorously measured or recorded, ammocoetes generally were burrowed in the top $12 \mathrm{~cm}$ of sand in the tank. Fish generally were unable to burrow in tank sections where the sand surface was dewatered because the dewatered sand quickly became compact. Although we did not observe a difference in the volume of the sand between the watered and dewatered conditions, the loss of the water in the interstitial spaces between sand particles resulted in a loss of lubrication, making it difficult to penetrate the sand surface. The dewatered sand was difficult to scoop up during our efforts to recover fish at the end of a trial. Even in cases where the surface was dewatered, but water was available 10-15 cm below the surface (for example, dewatering level 2), fish generally were unable to burrow. There was no evidence that fish were able to make significant movements across tank sections by moving through the sediment. All fish movements resulted from fish emerging from the sand in tank section 1 and moving down the slope, either across the surface of the sand if the tank section was dewatered, or by swimming if the tank section was submerged. Some fish, generally the smaller ones, had difficulty moving past depressions or ridges on the surface of the sand. Even small irregularities appeared to be significant obstacles to movement. Lamprey did not respond to the changing tank head pressure as the tank was dewatered. Fish movements generally were not observed until after the surface of tank section 1 was dewatered. For example, during the slow dewatering rate, dewatering level 1 was reached after about $7.5 \mathrm{~h}$, but fish movements for trials of dewatering levels 2 or 3 were not observed until 8-9 h after dewatering started. For the fast dewatering rate, fish movements for levels 2 and 3 began about 15 min after level 1 was reached. The delayed start to movements translated into stranding risk for levels 2 and 3 because the water was farther down the tank slope and some dewatered sediment had to be traversed in order to find sand wet enough to allow burrowing. Depending on the dewatering rate and level, there was a limited amount of time to take advantage of the availability of water before the final dewatered level was reached. For the slow dewatering rate, there was about $1.5 \mathrm{~h}$ between the time when the surface of section 1 was exposed (shortly after level 1 was reached), when fish started to move, and the time when level 2 was reached, when surface water was only available in lower tank sections. Similarly, for level 3, there was about $2.5 \mathrm{~h}$ between the start of movement and the final water level when the surfaces of all tank sections were dewatered. The fast dewatering rate took 10-15 min between the three dewatering levels, and fish showed movement after about $1.5 \mathrm{~h}$, which translates to about 15 min after level 1 was reached as dewatering continued to levels 2 or 3 .

Ammocoetes in the control series showed no movement and were recovered in section 1. At dewatering level 1, which was similar to the control conditions, all tank sections remained submerged. At the slow dewatering rate, 97 percent of the fish showed no movement and were recovered in section 1, and one fish was recovered in section 2 (fig. 3). During the fast dewatering rate, none of the ammocoetes moved out of section 1 (fig. 4). 


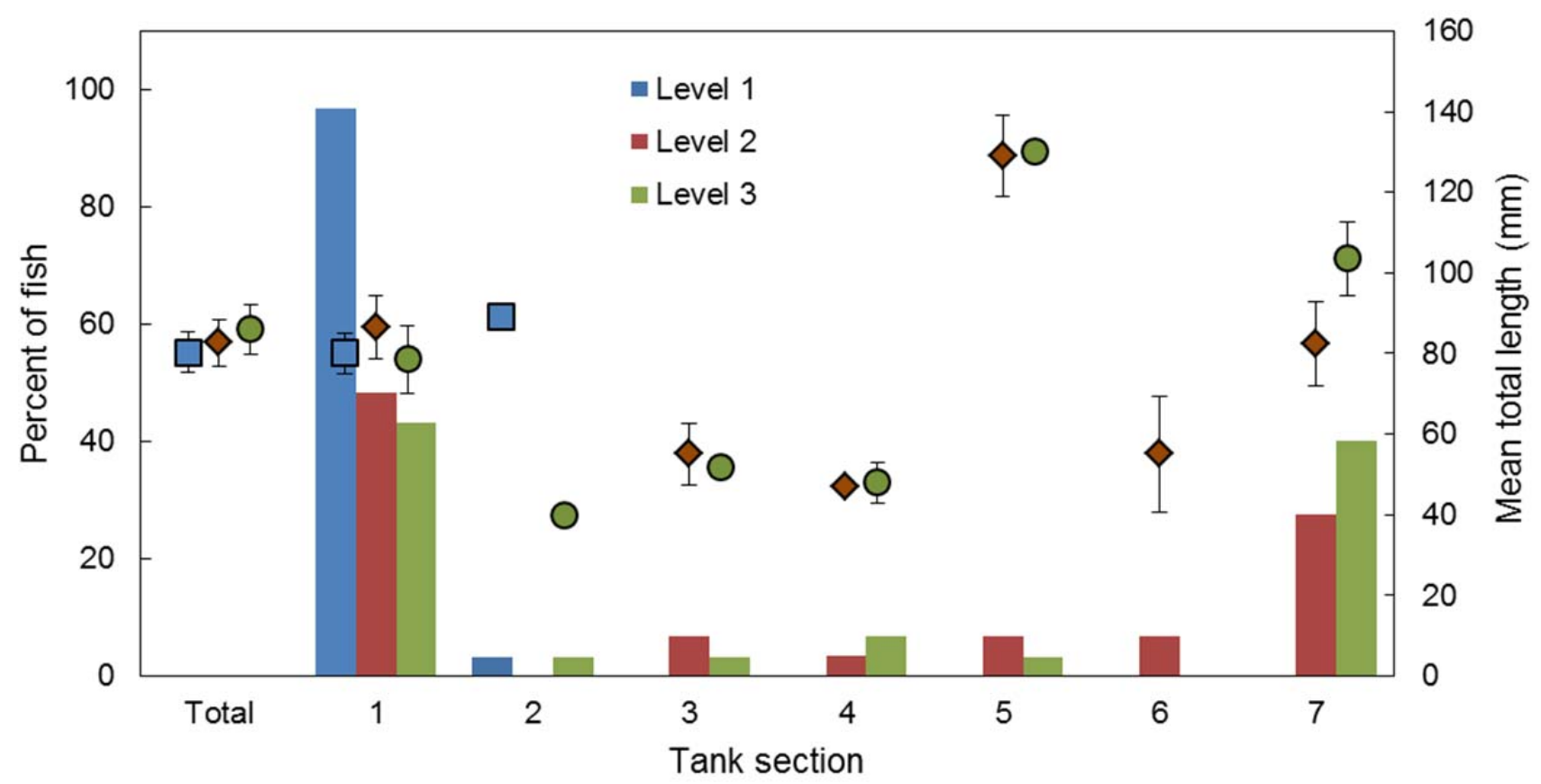

Figure 3. Graph showing percentage of fish (bars) and mean total length (points $\pm S E$ bars) of fish in each tank section for three dewatering levels tested at the slow (7.6 centimeters per hour) dewatering rate.

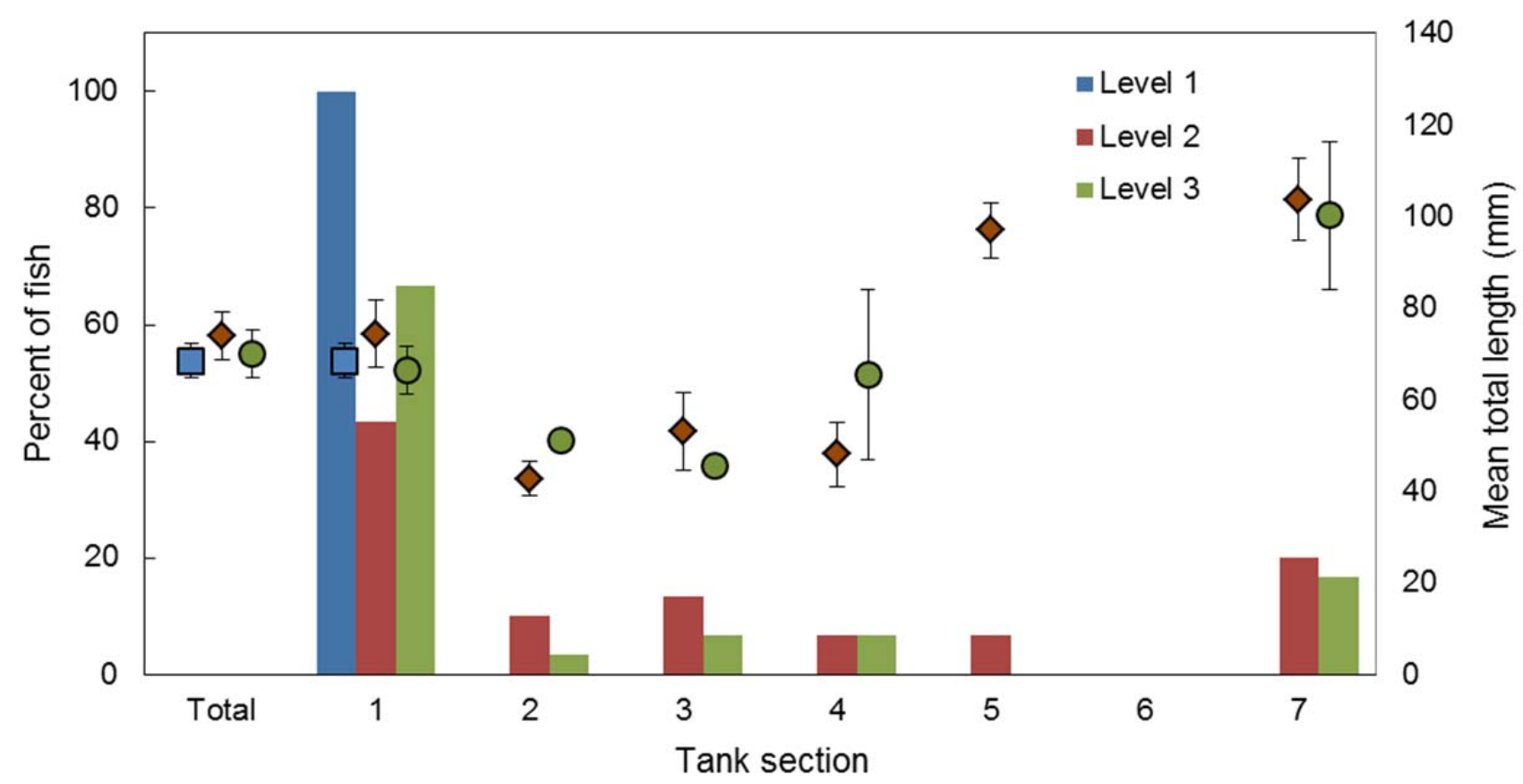

Figure 4. Graph showing percentage of fish (bars) and mean total length (points \pm SE bars) of fish in each tank section for three dewatering levels tested at the fast (51 centimeters per hour) dewatering rate. 
At the slow dewatering rate, the highest proportions of fish were recovered in the first tank section during all three dewatering levels (fig. 3). Lamprey in levels 2 and 3 trials showed movement, with less than one-half the fish remaining in section 1 (48 percent for level 2 and 43 percent for level 3). Small proportions of ammocoetes were in sections $2-6$, and section 7 had higher proportions (28 percent for level 2 and 40 percent for level 3; fig. 3). At dewatering level 2, the lower part of section 5 and all of sections 6 and 7 were submerged, but other tank sections were dewatered. Shortly after level 2 was reached, the sediment in the highest part of section 5 and all upper sections was hard and compacted, which may have prevented burrowing. Ammocoetes that reached the water swam throughout the watered tank sections for several minutes, and then burrowed very near the screen at the bottom edge of section 7 or the lateral edges of the tank near the screen. At level 3, none of the tank sections had water over the top of the sand, so fish that were recovered in the tank sections at the bottom of the slope either moved over the sand or were able to move from section 1 into a watered section as the water receded.

In the fast dewatering rate trials, fish were most concentrated in tank section 1 (fig. 4). At levels 2 and 3, 33 to 57 percent of the lamprey, respectively, moved out of section 1, down the slope, with relatively small proportions of fish recovered in tank sections 2-6, and the largest proportions of fish recovered in section 7 (20 percent for level 2 and 17 percent for level 3; fig. 4). As with the slow rate trials, fish that reached the water for level 2 showed a strong tendency to search sections 6 and 7 and then burrow near the screen at the lower end of section 7. No fish were recovered in tank section 6 for level 2 trials, although section 6 was fully submerged.

The rate of dewatering influenced the proportion of fish that moved and their final position in the tank. Trials at level 1 had almost identical fish movement findings for both the fast and slow dewatering rates. All but 1 of the 60 ammocoetes tested remained in tank section 1 . At level 2, more lamprey left section 1 during the fast rate than during the slow rate and moved to sections $2-4$, but fewer fish reached water in sections 5, 6 and 7 as compared to the slow rate (fig. 5A). Fish recovered in sections 2-4 showed the inclination to move in response to dewatering but did not reach a watered section. The slow rate stranded fewer fish (20 percent) than the fast rate (53 percent; table 4$)$. At the lowest dewatering level, when the sand was completely exposed in all tank sections, the dewatering rate influenced fish movements (fig. 5B). At the slow rate, approximately equal proportions (about 40 percent) of fish stayed in section 1 and reached section 7 , with a small proportion (17 percent) of fish recovered in the middle of the tank. At the fast rate, however, a large proportion of fish showed no movement (67 percent), and a small proportion of fish reached section 7 (17 percent; fig. 5B). More fish were able to traverse the tank slope under the slow dewatering rate. The fast dewatering rate stranded 50 percent of the lamprey that showed movement, whereas the slow rate stranded 29 percent of the moving fish (table 4).

Lamprey recovered in tank sections at the end of the slope were larger than fish stranded in the dewatered middle tank sections. The fish that remained in section 1 had a mean size similar to the overall mean size of fish at the start of the trial for both the slow (fig. 3) and fast (fig. 4) dewatering rates. Ammocoetes recovered from the middle tank sections generally were smaller than fish in section 1, and fish in section 7 tended to be the largest in all sections (figs. 3 and 4). The mean fish size for both dewatering rates and both levels was significantly larger for fish that found water or section 7, compared to stranded fish $(\mathrm{F}=4.02, \mathrm{df}=11, p>0.001$; fig. 6$)$. Stationary fish generally were not significantly different in size from the stranded fish or the fish that found water or section 7. 

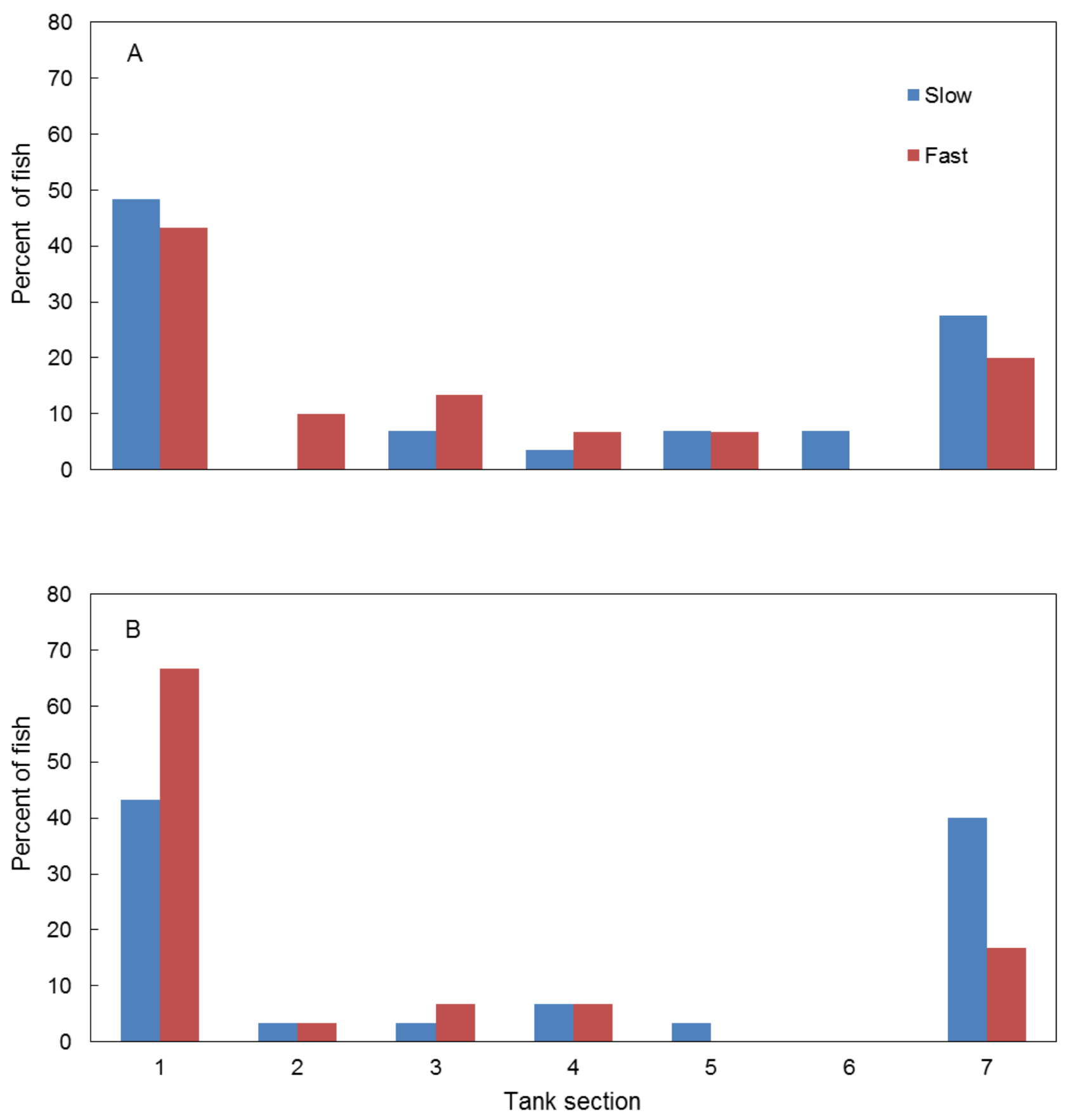

Figure 5. Graph showing percentage of fish recovered in each tank section following dewatering at the slow (7.6 $\mathrm{cm} / \mathrm{h})$ or fast $(51 \mathrm{~cm} / \mathrm{h})$ dewatering rate for $(A)$ level 2 or (B) level 3. 


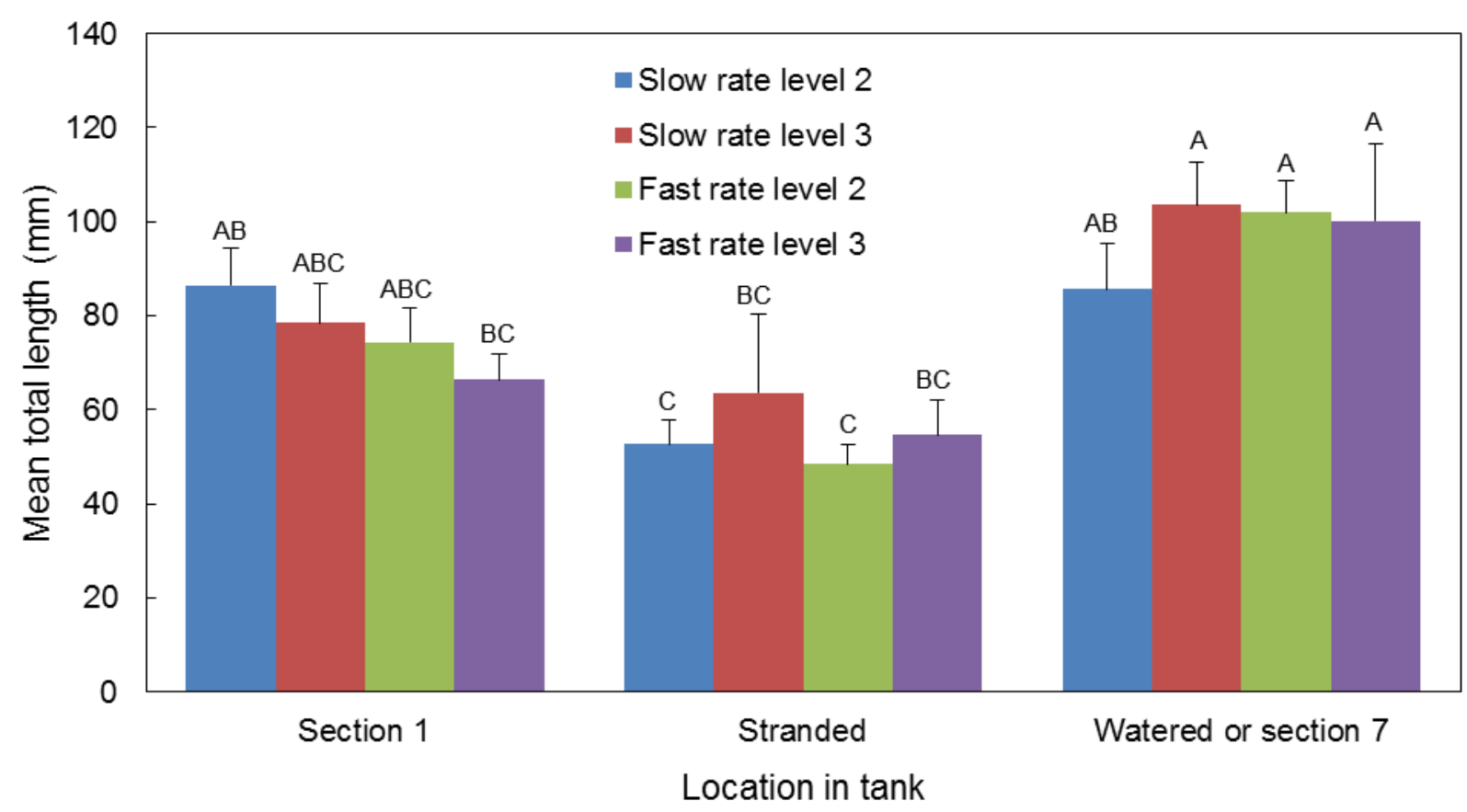

Figure 6. Graph showing mean total length of ammocoetes ( \pm SE bars) recovered in tank section 1 , stranded in middle tank sections, or watered tanks sections or section 7 for two dewatering rates and two dewatering levels. Fish were classified as stranded for dewatering level 2 if they were recovered in tank sections 2,3 , or 4 . For dewatering level 3 , fish were classified as stranded if they were recovered in tank sections 2-6. Letters above the bars are groups from Duncan's Multiple Range Test, as part of an Analysis of Variance (ANOVA) ( $F=4.02, d f=11$, $p>0.001)$. Groups without letters in common are significantly different.

Table 4. Number and percentage of fish outside tank section 1 , and fish classified as stranded and non-stranded for two dewatering rates and two dewatering levels.

[Fish were classified as stranded if they were in tank sections 2-4 for dewatering level 2 or in tank sections 2-6 for dewatering level 3. Fish were classified as non-stranded if they either found water (tank sections 5-7) for level 2 or reached section 7 for dewatering level 3]

\begin{tabular}{lcccc}
\hline \multicolumn{1}{c}{ Dewatering rate } & Dewatering level & $\begin{array}{c}\text { Number of fish } \\
\text { outside of tank } \\
\text { section 1 }\end{array}$ & $\begin{array}{c}\text { Number of (percent) } \\
\text { stranded fish }\end{array}$ & $\begin{array}{c}\text { Number of (percent) } \\
\text { non-stranded fish }\end{array}$ \\
\hline Slow & 2 & 15 & $3(20)$ & $12(80)$ \\
Fast & 2 & 17 & $9(53)$ & $8(47)$ \\
Slow & 3 & 17 & $5(29)$ & $12(71)$ \\
Fast & 3 & 10 & $5(50)$ & $5(50)$ \\
\hline
\end{tabular}




\section{Vertical Distribution Trials}

Vertical distribution trials were conducted to refine the experimental system for survival trials. Two exposure periods were tested ( 1 and $4 \mathrm{~h}$ ) and three replicate trials (with controls) were completed for each exposure period in September 2014, using 130 ammocoetes. The initial mean fish sizes for the dewatered and control groups were not significantly different for the six 1 -h exposure groups $(\mathrm{F}=1.22$, $\mathrm{df}=5, p=0.31)$ or the six 4-h exposure groups $(\mathrm{F}=1.00, \mathrm{df}=5, p=0.42)$. Both control trials showed similar trends; none of the ammocoetes emerged from the sand, and most were burrowed in the first tube section, up to a depth of $7.6 \mathrm{~cm}$ (table 5). Small proportions of fish were burrowed 7.6-15.2 cm deep (18-29 percent), and none of the ammocoetes burrowed deeper than $15.2 \mathrm{~cm}$. The vertical distribution of lamprey in 1- and 4-h exposure trials was similar. The largest proportion of fish were burrowed in the first tube section (0-7.6 cm deep), with the next highest proportion on the surface (table 5). During the 1-h trial, a small proportion of fish (4 percent) burrowed up to a depth of $15.2 \mathrm{~cm}$, but none of the dewatered ammocoetes burrowed deeper than $15.2 \mathrm{~cm}$. The size of lamprey at different depths was not significantly different in the $1-\mathrm{h}$ exposure trial $(\mathrm{F}=2.12, \mathrm{df}=2, p=0.13)$ or the 4-h exposure trial $(\mathrm{F}=0.07$, $\mathrm{df}=1, p=0.80$; table 6 ). Similarly, the size of lamprey at different depths for the control series was not significantly different during the 1 -h exposure trial $(\mathrm{F}=1.02, \mathrm{df}=1, p=0.32)$ or the 4-h exposure trial $(\mathrm{F}=1.92, \mathrm{df}=1, p=0.19)$.

Table 5. Number and percentages of larval lamprey in 1- or 4-hour exposures to control (submerged) and test (dewatered) conditions in three depth strata.

[Abbreviations: $\mathrm{cm}$, centimeter]

\begin{tabular}{lrr|rr}
\hline \multirow{2}{*}{ Strata } & \multicolumn{2}{c|}{ 1-hour exposure } & \multicolumn{2}{c}{ 4-hour exposure } \\
\cline { 2 - 5 } & Control & \multicolumn{1}{c}{ Test } & Control & Test \\
\hline Fish on surface (percent) & 0 & $21(44)$ & 0 & $17(35)$ \\
Fish 0-7.6 cm deep (percent) & $12(71)$ & $25(52)$ & $14(82)$ & $31(65)$ \\
Fish 7.6-15.2 cm deep (percent) & $5(29)$ & $2(4)$ & $3(18)$ & 0 \\
Total number of fish & 17 & 48 & 17 & 48 \\
\hline
\end{tabular}


Table 6. Number, mean total length, and standard deviation of larval lamprey in 1- or 4-hour exposures to control (submerged) and test (dewatered) conditions in three depth strata.

[Abbreviations: TL, total length; mm, millimeter; SD, standard deviation; $\mathrm{cm}$, centimeter]

\begin{tabular}{lrr|rr}
\hline \multirow{2}{*}{ Strata } & \multicolumn{2}{c|}{ 1-hour exposure } & \multicolumn{2}{c}{ 4-hour exposure } \\
\cline { 2 - 5 } & \multicolumn{1}{c}{ Control } & \multicolumn{1}{c}{ Test } & \multicolumn{1}{c}{ Control } & Test \\
\hline Mean TL (mm [SD]) & $82(21.7)$ & $77(18.7)$ & $56(16.7)$ & $63(24.3)$ \\
& & & & \\
Fish on surface mean TL (mm [SD]) & 0 & $72(17.2)$ & 0 & $64(28.3)$ \\
Fish 0-7.6 cm deep mean TL (mm [SD]) & $85(2.5)$ & $82(19.4)$ & $53(16.1)$ & $62(22.3)$ \\
Fish 7.6-15.2 cm deep mean TL (mm [SD]) & $73(19.3)$ & $65(4.9)$ & $67(17.2)$ & 0 \\
Total number of fish & 17 & 48 & 17 & 48 \\
\hline
\end{tabular}

\section{Survival Trials}

Three trials evaluating lamprey survival following dewatering were conducted from November 2014 to January 2015 under ambient air temperatures and humidity levels (table 7). A total of 647 ammocoetes were used in survival trials, such that within each trial, each of the seven exposure times and the control were replicated three times, with nine fish. The ammocoetes used in trial 3 were larger than the previous trials (fig. 7), but they were not significantly different from treatment or control groups for trials 1 or $2(\mathrm{~F}=1.50, \mathrm{df}=5, p=0.19)$. No injuries were observed in fish recovered following the dewatering exposure period. Ammocoetes recovered from the surface of the tubes after extended exposures $(\geq 12 \mathrm{~h})$ generally were covered in sand from moving around on the sand surface and appeared to be desiccated.

The sand in the survival trial tubes had a vertical moisture gradient (fig. 8). The control sand samples had the highest percent moisture, representing the condition of the sand immediately after the tubes were removed from water (fig. 8). There were no significant differences among the surface or bottom mean moisture percentages for any of the control trials $(\mathrm{F}=1.19, \mathrm{df}=5, p=0.37)$. The mean moisture content was significantly less in the surface sand samples than in the bottom sand samples for all treatment trials $(\mathrm{F}=223.8, \mathrm{df}=5, p<0.001)$. The mean surface moisture content of the sand was not significantly different among the three trials (table 8). The biggest difference among the trials was that the mean moisture content was significantly less for the sand at the bottom of the tubes in trial 1 than in the tube bottoms for trials 2 and 3 (table 8). Mean moisture content was lowest in sand at both the top and bottom positions in trial 1 (table 8). Exposure duration did not influence the moisture content of the sand at the bottom of the tubes $(\mathrm{F}=0.58, \mathrm{df}=6, p=0.75)$, which ranged from 31.2 to 32.3 percent moisture. The moisture content of the sand at the top of the tubes, however, was significantly different among the exposure durations $(\mathrm{F}=9.06, \mathrm{df}=6, p<0.001)$, with the highest moisture content for the time 0 sample (13.5 percent) and the lowest moisture content at $24 \mathrm{~h}$ of exposure (11.0 percent). 


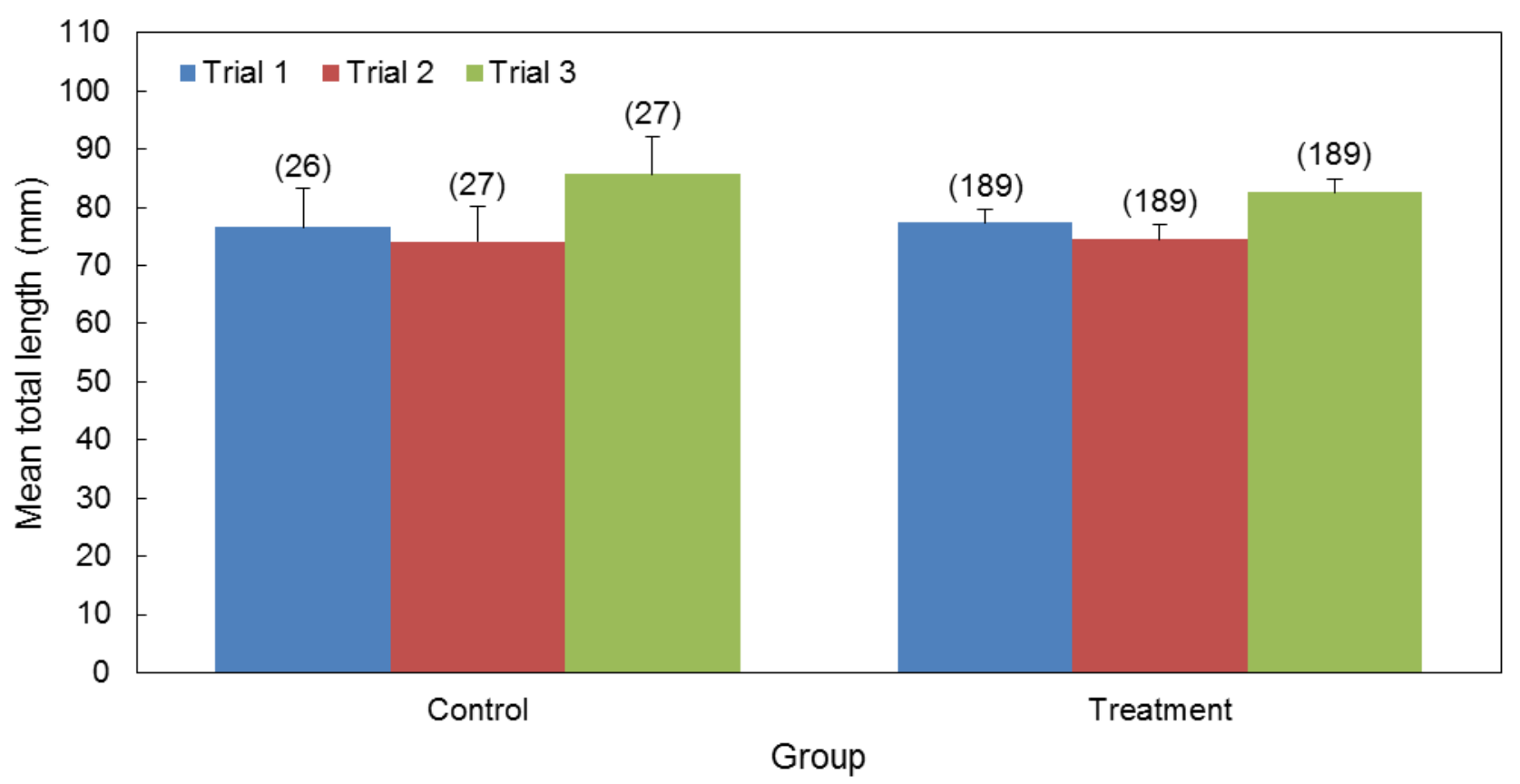

Figure 7. Graph showing mean total length of ammocoetes ( \pm SE bars) used in the control and treatment (dewatered) groups for three trials evaluating the survival of fish following dewatering. Numbers in parentheses above the bars are the group sample size.

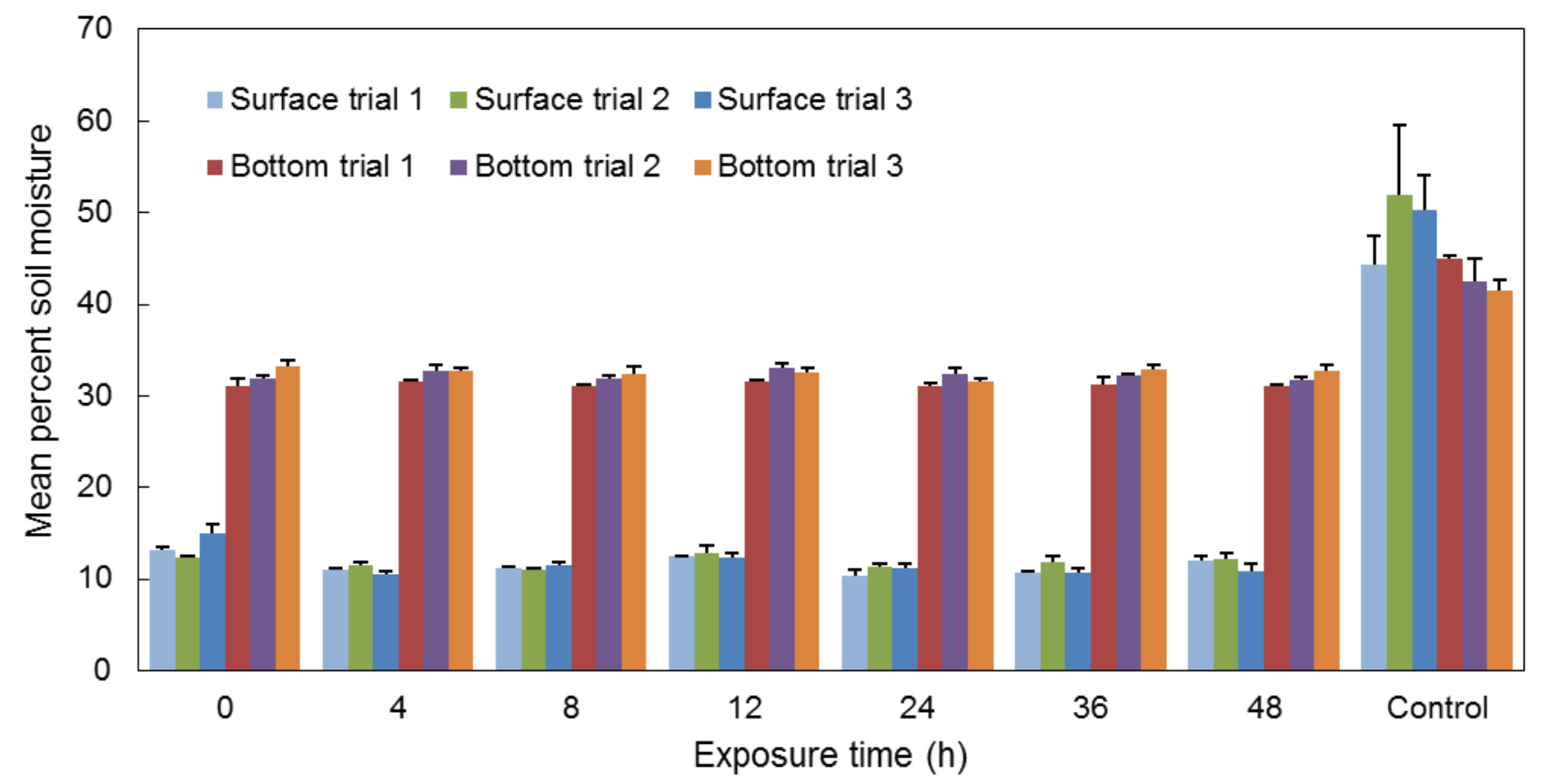

Figure 8. Graph showing mean percent soil moisture ( \pm SE bars) in sample tubes dewatered for a series of exposure times and three trials. Sediment was sampled from the top center of the tubes (surface) and at a point 5 centimeters from the bottom of the tube, in the center (bottom). 
Table 7. Trial number, trial date, air temperature, humidity, and dew point for three dewatering survival trials.

[Abbreviations: ${ }^{\circ} \mathrm{C}$, degrees Celsius; SD, standard deviation]

\begin{tabular}{c|c|cc|cc|c}
\hline \multirow{2}{*}{ Trial No. } & \multirow{2}{*}{ Trial date } & \multicolumn{2}{|c|}{$\begin{array}{c}\text { Air temperature } \\
\left({ }^{\circ} \mathrm{C}\right)\end{array}$} & \multicolumn{2}{c|}{$\begin{array}{c}\text { Humidity } \\
\text { (percent) }\end{array}$} & \multirow{2}{*}{$\begin{array}{c}\text { Dew point } \\
\left({ }^{\circ} \mathrm{C}\right)\end{array}$} \\
\cline { 3 - 6 } & & $\begin{array}{c}\text { Mean } \\
\text { (SD) }\end{array}$ & Range & $\begin{array}{c}\text { Mean } \\
\text { (SD) }\end{array}$ & Range & \\
\hline 1 & November 4, 2014 & $17.3(0.7)$ & $16.0-18.1$ & $68(3)$ & $65-72$ & 10 \\
2 & December 2, 2014 & $13.0(1.1)$ & $11.2-14.4$ & $46(3)$ & $42-49$ & 2 \\
3 & January 13, 2015 & $13.6(1.0)$ & $12.7-15.2$ & $59(3)$ & $56-65$ & 6 \\
\hline
\end{tabular}

Table 8. Soil moisture content for the surface and bottom of sample tubes in three dewatering survival trials.

[The Duncan group indicates the results of Duncan's Multiple Range Test conducted following an Analysis of Variance (ANOVA) ( $\mathrm{F}=223.8$, degrees of freedom=5, $p<0.001)$ ]

\begin{tabular}{clcccc}
\hline $\begin{array}{c}\text { Trial } \\
\text { No. }\end{array}$ & Location & $\begin{array}{c}\text { Number of } \\
\text { sample } \\
\text { tubes }\end{array}$ & $\begin{array}{c}\text { Mean } \\
\text { (percent) }\end{array}$ & $\begin{array}{c}\text { Standard } \\
\text { deviation }\end{array}$ & $\begin{array}{c}\text { Duncan } \\
\text { group }\end{array}$ \\
\hline 1 & Surface & 21 & 11.56 & 1.08 & $\mathrm{C}$ \\
& Bottom & 21 & 31.21 & 0.72 & $\mathrm{~B}$ \\
2 & Surface & 21 & 11.87 & 0.93 & $\mathrm{C}$ \\
& Bottom & 21 & 32.28 & 0.82 & $\mathrm{~A}$ \\
3 & Surface & 21 & 11.76 & 1.71 & $\mathrm{C}$ \\
& Bottom & 21 & 32.59 & 0.92 & $\mathrm{~A}$ \\
\hline
\end{tabular}


Overall mortality in the dewatered groups for three survival trials was 23.4 percent (133 fish), and mortality increased with exposure time (fig. 9). Mortality was consistently higher in trial 1 than in other trials (fig. 9). Of the 133 mortalities, 18 percent ( 24 fish) were alive at the end of the exposure period, but died during the 48-h post-exposure holding period. Most of these delayed mortalities ( 75 percent) were for exposure periods of $24 \mathrm{~h}$ or longer, and almost one-half of them (46 percent) were from trial 3. Most of the post-sampling holding mortality ( 88 percent) occurred during the initial $24 \mathrm{~h}$ of the post-sampling holding period. There were no mortalities among the 80 ammocoetes in control groups for the three trials.

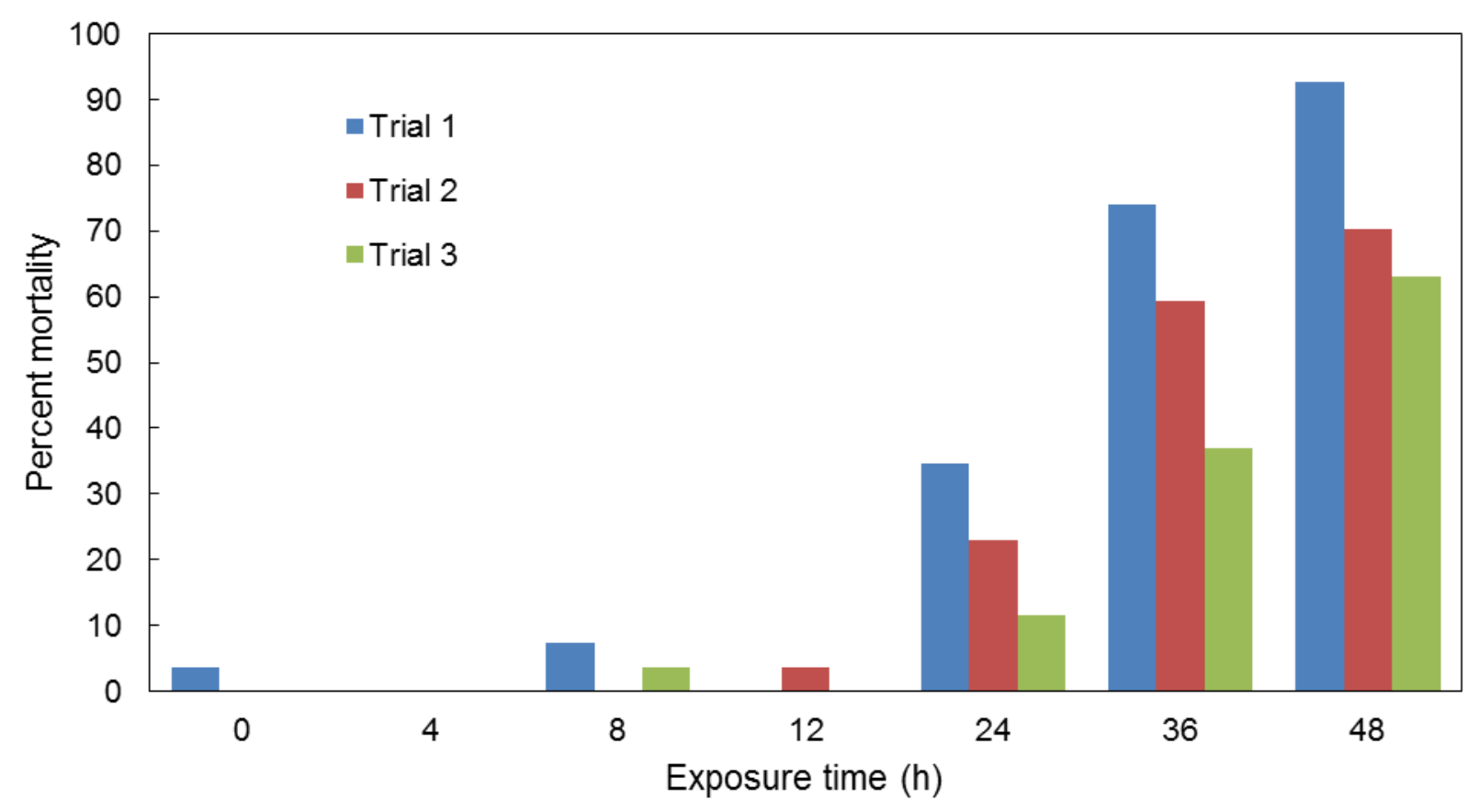

Figure 9. Graph showing percent mortality for larval lamprey exposed to dewatered conditions for a series of exposure times and for three experimental trials. 
Ammocoetes that were lethargic at the time of sampling comprised 10 percent (59 fish) of the treatment group and only occurred in exposure periods that exceeded $24 \mathrm{~h}$. The distribution of lethargic fish was skewed, with almost one-half (44 percent) occurring in trial 3, and approximately equal proportions in trials 1 ( 29 percent) and 2 (27 percent). More lethargic fish were on the surface of the sediment (64 percent) than burrowed in the sediment (36 percent). Most fish categorized as lethargic at the end of the exposure period were alive and actively swimming when sampled following the 48-h holding period (63 percent). A small number of fish were lethargic after $48 \mathrm{~h}$ ( 8 percent), and 29 percent of the fish were dead within $24 \mathrm{~h}$ of the end of the exposure period.

A logistic regression model was used to predict the chance of larval lamprey surviving or dying following dewatering based on the set of selected variables in the final model. The response variable was the survival of ammocoetes exposed to dewatering conditions, and the predictor variables included the survival trial, the exposure period, the position of the fish either burrowed in or on the surface of the sand in the tubes, and fish size (table 2). Two models were evaluated. Model 1 included the four predictor variables, and model 2 included the four predictor variables and four interaction terms that could potentially have biologically meaningful effects. The interaction terms were exposure*fish size, exposure*position, position*fish size, and exposure*trial. Based on the Wald $\chi^{2}$ value at the 95-percent significance level, all four interaction terms were removed, and model 1 was selected as the final model. There was no evidence of lack of fit in the final model (Likelihood ratio test $\chi^{2}=418.57, p<0.001$ ), and descriptive statistics are presented in table 9.

Table 9. Descriptive statistics for the final logistic regression model selected to represent the survival of larval lamprey following exposure to dewatering conditions.

[df, degrees of freedom; SE, standard error]

\begin{tabular}{|c|c|c|c|c|c|}
\hline Parameter & df & Coefficient & SE & $x^{2}$ value & P \\
\hline Intercept & 1 & -1.14 & 0.65 & 3.04 & 0.082 \\
\hline Exposure $\leq 24 \mathrm{~h}$ & 1 & -3.95 & 0.59 & 44.39 & $<0.001$ \\
\hline Exposure $36 \mathrm{~h}$ & 1 & -6.68 & 0.71 & 88.06 & $<0.001$ \\
\hline Exposure $48 \mathrm{~h}$ & 1 & -8.71 & 0.91 & 92.68 & $<0.001$ \\
\hline Position burrowed & 1 & 1.46 & 0.41 & 12.06 & 0.0005 \\
\hline Fish Size & 1 & 0.07 & 0.009 & 58.58 & $<0.001$ \\
\hline Trial 2 & 1 & 1.69 & 0.48 & 12.55 & 0.004 \\
\hline Trial 3 & 1 & 2.22 & 0.50 & 19.62 & $<0.001$ \\
\hline $\begin{array}{l}\text { Likelihood ratio test, } \\
\text { number }=567\end{array}$ & $\chi 2=418.57$ & $\mathrm{df}=7 p<0.001$ & & & \\
\hline
\end{tabular}


The amount of time fish were exposed to the dewatered condition had a significant effect on their survival. There was very limited mortality for exposure periods of less than $24 \mathrm{~h}$, and mortality increased steadily as the exposure period increased (fig. 9). For the logistic regression, the 12-h or less exposure group was used as the reference group for comparisons. The odds ratios, modeled for the probability of death, show that larval lamprey exposed to dewatered conditions for $24 \mathrm{~h}$ were about 52 times more likely to die than fish exposed for $12 \mathrm{~h}$ or less (table 10). Similarly, fish exposed for 36 and $48 \mathrm{~h}$ were much more likely (about 794 times for $36 \mathrm{~h}$ and more than 999 times for $48 \mathrm{~h}$ ) to die than fish exposed for $12 \mathrm{~h}$ or less (table 10).

The logistic regression model showed a significant trial effect. Although the survival trends in the three trials were similar, mortality rates were consistently highest in trial 1 and lowest in trial 3 (fig. 9). The first trial was used as the reference group for comparisons. Based on the odds ratios modeled for the probability of survival, lamprey were about 5 times more likely to survive in trial 2 than in trial 1 (table 11). Similarly, fish were about 9 times more likely to survive in trial 3 than in trial 1 (table 11). Larval lamprey that remained burrowed in the substrate following dewatering had improved survival. Overall, 60 percent of ammocoetes were on the surface of the substrate at the end of their exposure period (table 12), and this trend was consistent across exposure periods (table 13). Fish that emerged from the substrate were significantly smaller than fish that remained in the sand (table 12; $\mathrm{F}=11.8, \mathrm{df}=1, p=0.006$ ). Hourly monitoring immediately following dewatering showed that fish generally emerged shortly after the sand was dewatered (57-60 percent of fish), or remained burrowed throughout the exposure period (fig. 10). The odds ratio from the logistic regression modeled for the probability of survival indicated that lamprey burrowed in the substrate were about 4 times more likely to survive than fish on the surface (table 11).

Larger ammocoetes survived dewatering exposure better than smaller ammocoetes . The odds ratio from the logistic regression predicting the chances of survival was 1.07, meaning that the odds are just more than 1 time higher that lamprey will survive for every 1-mm increase in TL (table 11). To better understand this effect, we also modeled a $10-\mathrm{mm}$ increase in TL and determined that the odds of surviving increased by a factor of 2 for every $10-\mathrm{mm}$ increase in TL. Ammocoetes initially stocked into the tubes for the survival trials were similarly sized across the three trials $(\mathrm{F}=1.50, \mathrm{df}=5, p=0.19$; fig. 7$)$ and the exposure periods (fig. 11), so there was not an initial size bias during the experiment. The predicted probabilities of mortality for a 48-h exposure based on TL of fish, and fish position in or on the substrate are presented in figure 12. We used the regression model coefficients from table 10 to calculate these predicted values. Although figure 12 represents a single exposure period, it is clear that small fish have significantly higher risk of mortality than larger fish and that fish on the surface are consistently more likely to die, regardless of size. 


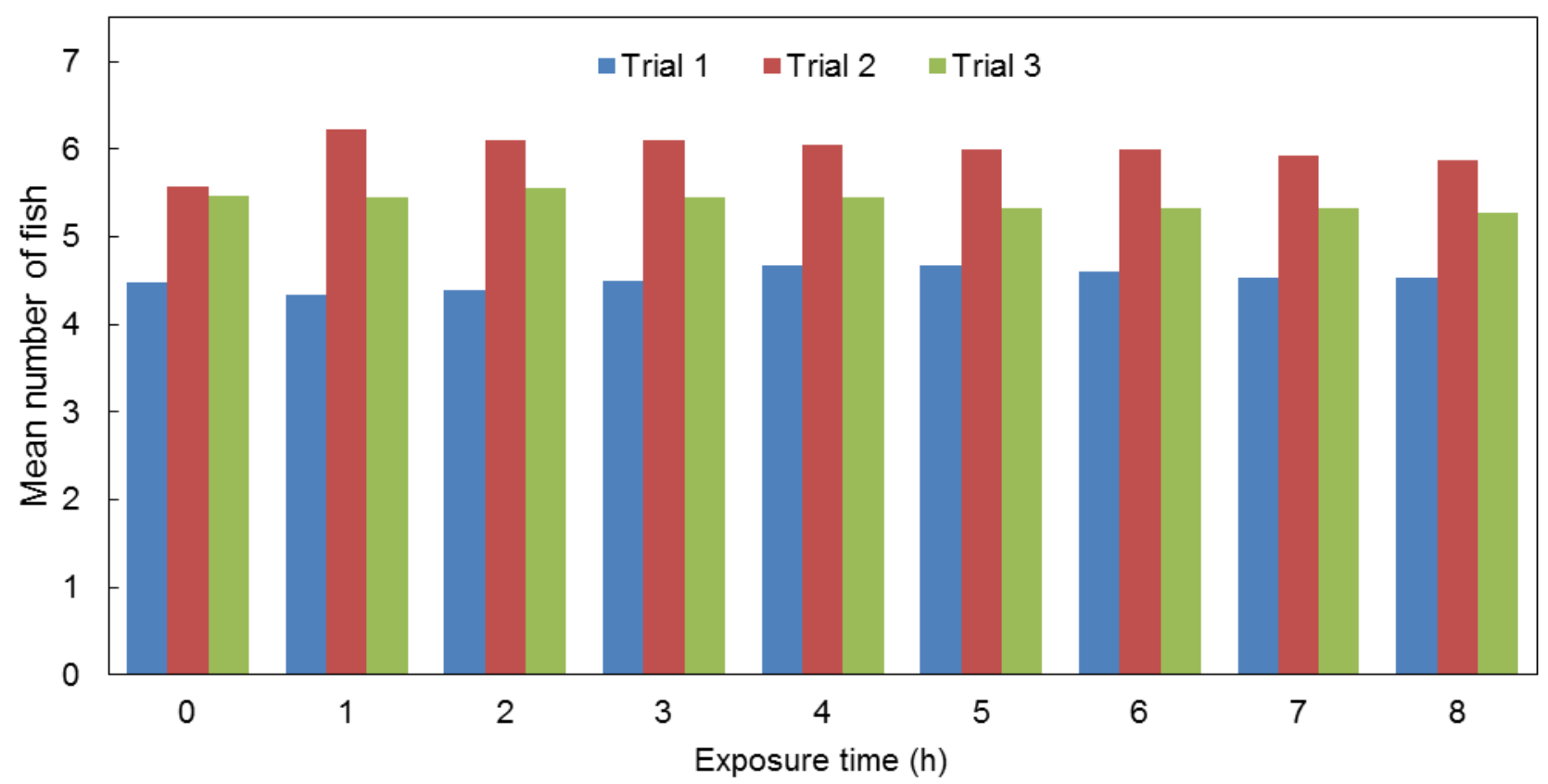

Figure 10. Graph showing mean number of fish on the surface of sample tubes for the first 8 hours of exposure to dewatered conditions for three experimental trials.

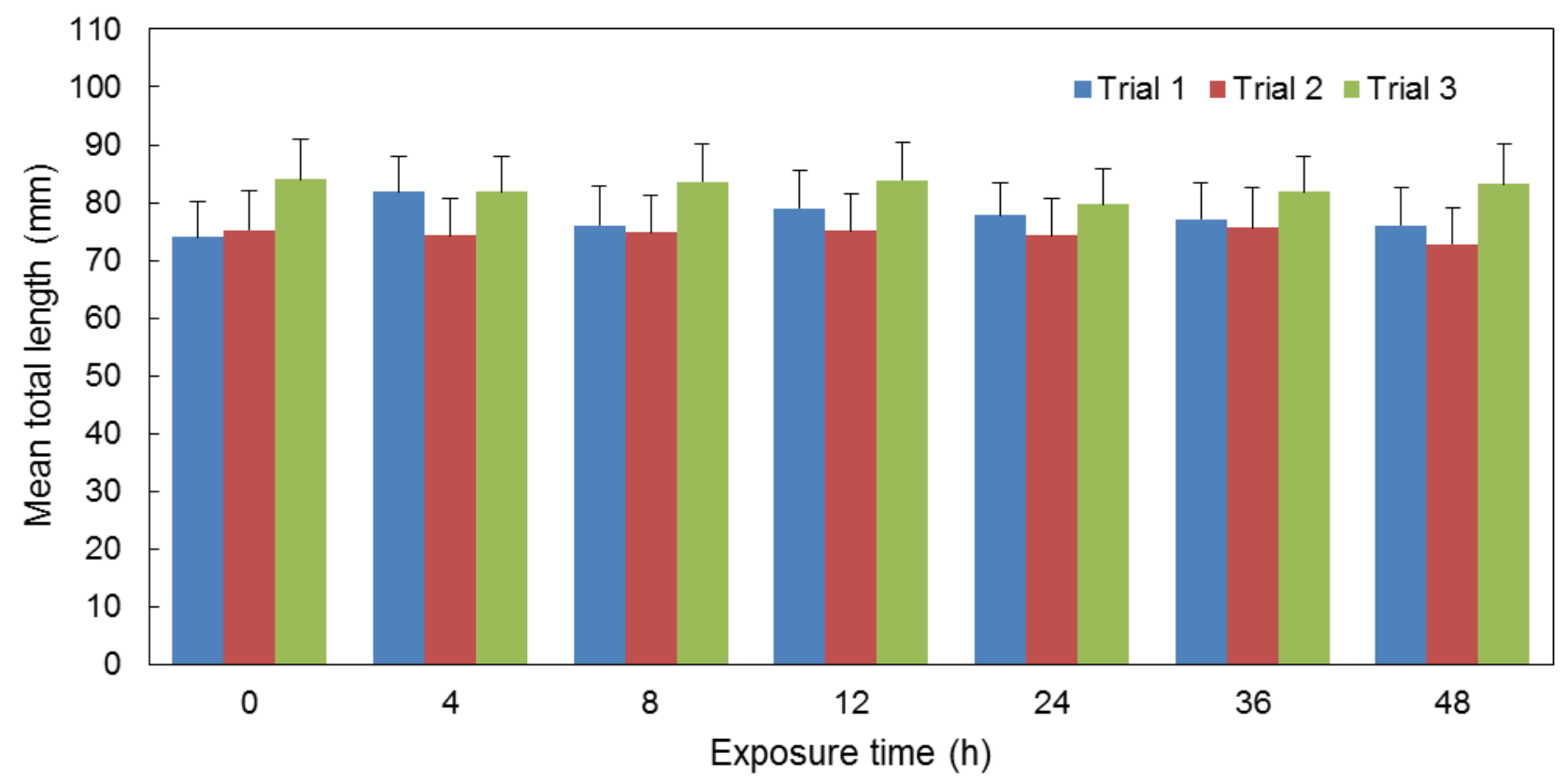

Figure 11. Graph showing mean total length of ammocoetes (+ SE bars) used in three experimental trials for a range of exposure times. 

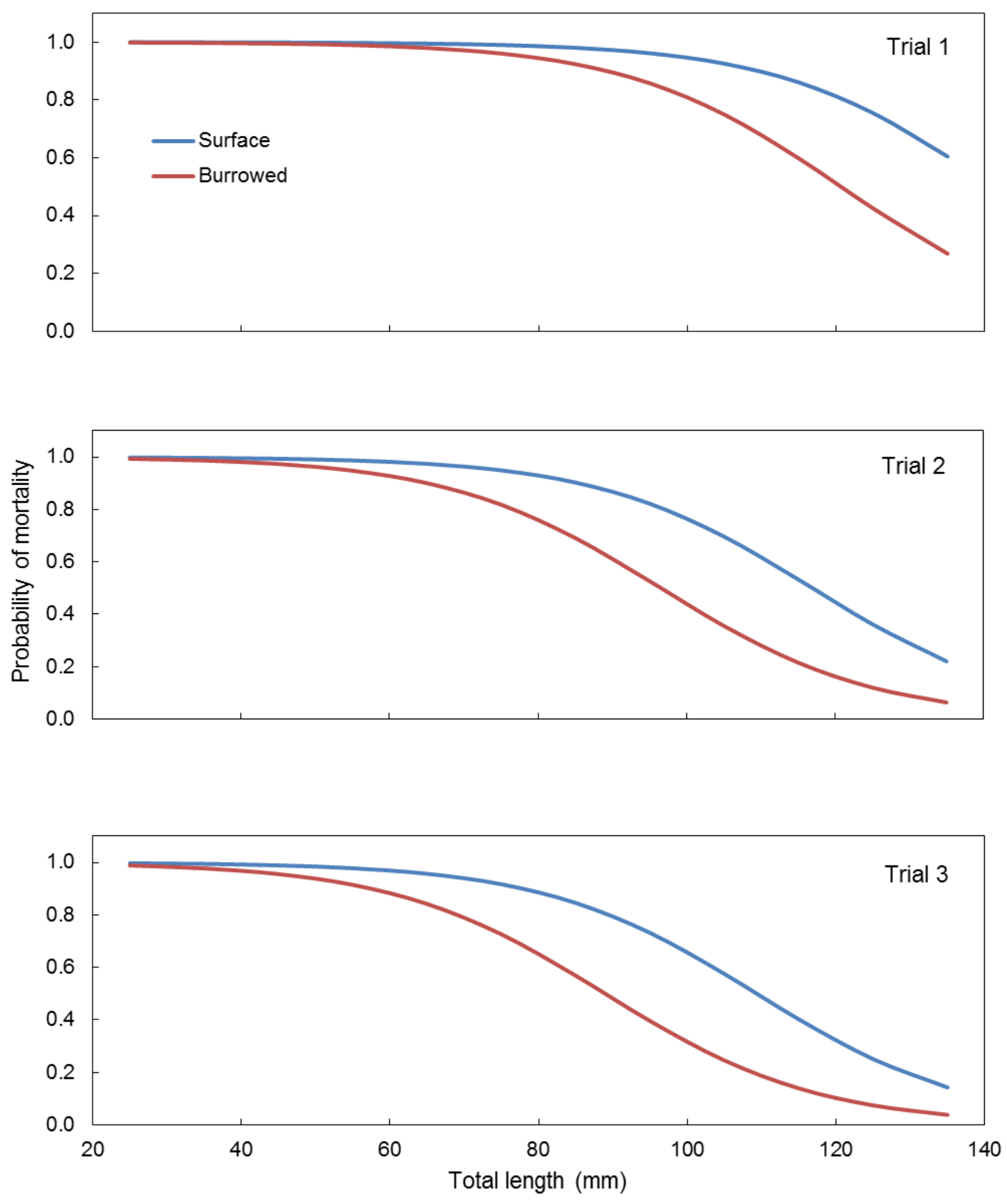

Figure 12. Graphs showing predicted probability of mortality for a 48-hour exposure to dewatered conditions based on total length of fish, whether they were on the surface of the sediment (surface) or burrowed in the sediment (burrowed) for each of three experimental trials. 
Table 10. Odds ratios for effects modeled for the probability of death in the final logistic regression model selected to represent the survival of larval lamprey following exposure to dewatered conditions.

$[\leq$, less than or equal to; $>$, greater than $]$

\begin{tabular}{lcc}
\hline \multicolumn{1}{c}{ Effect } & $\begin{array}{c}\text { Odds ratio } \\
\text { point } \\
\text { estimate }\end{array}$ & $\begin{array}{c}\text { 95-percent } \\
\text { confidence limits }\end{array}$ \\
\hline Exposure $\leq 12$ vs $24 \mathrm{~h}$ & 51.99 & $16.26,166.21$ \\
Exposure $\leq 12$ vs 36 h & 794.24 & $196.91,>999$ \\
Exposure $\leq 12$ vs 48 h & $>999$ & $>999,>999$ \\
\hline
\end{tabular}

Table 11. Odds ratios for effects modeled for the probability of survival in the final logistic regression model selected to represent the survival of larval lamprey following exposure to dewatered conditions.

\begin{tabular}{lcc}
\hline \multicolumn{1}{c}{ Effect } & $\begin{array}{c}\text { Odds ratio } \\
\text { point } \\
\text { estimate }\end{array}$ & $\begin{array}{c}\text { 95-percent } \\
\text { confidence limits }\end{array}$ \\
\hline Position surface vs burrowed & 4.28 & $1.88,9.71$ \\
Size & 1.07 & $1.05,1.09$ \\
Trials 1 vs 2 & 5.41 & $2.13,13.78$ \\
Trials 1 vs 3 & 9.21 & $3.45,24.58$ \\
\hline
\end{tabular}


Table 12. Number, percent, mean total length, standard deviation and range of ammocoetes on the surface and burrowed into the sediment at the time of sampling for dewatering survival trials.

[Abbreviations: N, number; TL, total length; mm, millimeter; SD, standard deviation]

\begin{tabular}{llccc}
\hline \multicolumn{1}{c}{ Position } & $\begin{array}{c}\text { Number of } \\
\text { ammocoetes } \\
\text { (percent) }\end{array}$ & $\begin{array}{c}\text { Mean TL } \\
(\mathbf{m m})\end{array}$ & SD & Range \\
\hline Surface & $341(60)$ & 74 & 32.3 & $30-142$ \\
Burrowed & $225(40)$ & 84 & 34.0 & $35-142$ \\
\hline
\end{tabular}

Table 13. Summary of the number and percent of lamprey on the surface or burrowed into the sediment for three dewatering trials and seven exposure times.

\begin{tabular}{|c|c|c|c|c|c|c|c|c|}
\hline \multirow[t]{2}{*}{ Trial } & \multirow[t]{2}{*}{ Position } & \multicolumn{7}{|c|}{$\begin{array}{l}\text { Exposure time } \\
\text { (hours) }\end{array}$} \\
\hline & & 0 & 4 & 8 & 12 & 24 & 36 & 48 \\
\hline \multirow[t]{2}{*}{1} & Surface & 15 & 14 & 15 & 12 & 16 & 15 & 11 \\
\hline & Burrowed & 12 & 13 & 12 & 15 & 10 & 12 & 16 \\
\hline \multirow[t]{2}{*}{2} & Surface & 19 & 20 & 19 & 19 & 17 & 20 & 16 \\
\hline & Burrowed & 8 & 7 & 8 & 8 & 10 & 7 & 11 \\
\hline \multirow[t]{2}{*}{3} & Surface & 19 & 18 & 18 & 17 & 15 & 12 & 14 \\
\hline & Burrowed & 8 & 9 & 9 & 10 & 12 & 15 & 13 \\
\hline \multirow[t]{2}{*}{ Total } & $\begin{array}{l}\text { Surface } \\
\quad \text { (percent) }\end{array}$ & $53(65)$ & $52(64)$ & $52(64)$ & $48(59)$ & $48(59)$ & $47(58)$ & $41(51)$ \\
\hline & $\begin{array}{l}\text { Burrowed } \\
\text { (percent) }\end{array}$ & $28(35)$ & $29(36)$ & $29(36)$ & $33(41)$ & $32(41)$ & $34(42)$ & $40(49)$ \\
\hline
\end{tabular}




\section{Discussion}

Ammocoetes were able to survive short exposure to dewatering, but mortality increased steadily when exposure time exceeded $24 \mathrm{~h}$. By $48 \mathrm{~h}$, mortality was consistently greater than 60 percent, and greater than 90 percent in trial 1 . Very limited mortality ( $<7$ percent) occurred for any exposure period less than $24 \mathrm{~h}$. The three mortality trials all showed increasing mortality through time. . Mortality was consistently highest in trial 1 at any given exposure period and consistently lowest in trial 3 . Air temperature and humidity during the different trials may have influenced survival. Mean air temperature $\left(17.3{ }^{\circ} \mathrm{C}\right)$, relative humidity $\left(68\right.$ percent), and dew point temperature $\left(10{ }^{\circ} \mathrm{C}\right)$ were highest in trial 1 . The high dew point is evidence for the highest amount of moisture in the air, independent of air temperature. Mortality was at intermediate levels, and mean air temperature $\left(13.0^{\circ} \mathrm{C}\right)$, relative humidity $(46$ percent $)$, and dew point temperature $\left(2^{\circ} \mathrm{C}\right)$ were lowest in trial 2 . There is not a clear relationship between the mortality observed in the trials and the moisture in the air, as expressed by either relative humidity or dew point temperature, but the influence of air temperature seems clearer. Mean air temperature for trial 1 was about $4{ }^{\circ} \mathrm{C}$ warmer than for trials 2 or 3 , which were similar to each other (mean temperatures differed by $0.6^{\circ} \mathrm{C}$ ). The substrate (sand) moisture content was lower for trial 1 than for the other trials, possibly contributing to the elevated mortality for ammocoetes trying to respire on dewatered sediment. A final, potential contributor to the difference in mortality between the trials was the initial size of the fish used in trial 3. Mean TL of fish was larger for trial 3 than for trials 1 or 2, but the difference was not significant. The logistic regression model showed, however, that larger fish had greater odds of surviving dewatering, and even a small difference in size $(10 \mathrm{~mm})$ made a difference. As the mean air temperature was similar between trials 2 and 3, perhaps the larger fish in trial 3 contributed to the decreased mortality for trial 3.

The fast dewatering rate stranded more ammocoetes in the middle tank sections than the slow rate. Lamprey did not respond to the changing head pressure as the tank was being dewatered, and they only emerged and began moving some time after the surface of the sand in tank section 1 was exposed. The delayed emergence, combined with the fast dewatering rate, increased the distance fish had to travel to reach a wetted surface or water where re-burrowing could occur. The slow dewatering rate stranded fewer fish, especially at dewatering level 2, where fish could find wet sand and water in the lower three tank sections. Ammocoete movements for dewatering level 1 were very similar to the control trials, and only a single fish moved out of section 1 . This suggests that even a small amount of water over the sediment is protective and fish stay burrowed as if they were covered with deeper water.

Fish size significantly influenced the movement and survival of ammocoetes following exposure to dewatering conditions. In movement trials, small fish struggled to move across the surface of dewatered tank sections, whereas large fish made the transit more readily. Lamprey that moved down the tank slope far enough to find water or the end of the tank at section 7 were significantly larger than fish that were stranded in middle tank sections. In settings like the Columbia River, shorelines where ammocoetes burrow will most likely have irregular surfaces that pose more significant challenges to travel than the relatively smooth sand surface used in our tests. Under more natural settings, perhaps even relatively large ammocoetes may not move effectively and, therefore, may be vulnerable to elevated air temperatures, sun exposure, and predation. The survival trials showed that small fish were more likely to die following dewatering. The odds of surviving dewatering increase by a factor of 2 for every $10 \mathrm{~mm}$ increase in TL. Taken together, the findings of the movement and survival trials suggest that small ammocoetes are very vulnerable to dewatering because they have a greater need to find water to avoid dying but have a more limited ability to move to find water. In the Columbia River hydropower system, extended dewatering events of densely populated habitats could result in high mortality for multiple year classes of lamprey. 
Burrowing in the sediment provided a survival advantage during dewatering tests. Ammocoetes that burrowed in the sediment during the survival trials were more than 4 times more likely to survive than those on the surface of the sediment, across all size classes. Fish on the surface, however, were smaller than those that remained burrowed. Throughout the movement and dewatering trials, about onehalf of the fish emerged from the sand following exposure to dewatering conditions and about one-half stayed burrowed. They generally were not burrowed very deep in the sand, and they did not emerge immediately after the sand surface was dewatered, but shortly afterwards. On the Columbia River or tributary shorelines, fish that emerge from the sediment may or may not be at greater risk of dying than fish that do not emerge, depending on the duration and rate of dewatering and the slope of the shoreline. If lamprey emerge and can re-gain access to water by traversing dewatered habitat, they will be more likely to survive than fish that remained burrowed but were exposed to a longer, and potentially fatal, duration of dewatering.

Some of the findings from this research caused us to modify our approach as the work progressed and to consider additional changes for future experimental work. We are curious as to whether our choice of sand as a substrate for use in these trials may have influenced some of the findings. Once dewatered, the sand used for these experiments quickly became hard and, to our knowledge, almost completely eliminated the option for fish to re-burrow. We selected sand for this work because we have been using the substrate during our rearing and culture efforts for many years, and ammocoetes readily burrow in it when it is provided to them in tanks. Additionally, we thought it was a reasonable choice because the median grain size $(0.378 \mathrm{~mm})$ is within a grain size category $(<0.5$ $\mathrm{mm}$ ) commonly found in the lower Columbia River where ammocoetes are detected (Jolley and others, 2014). A potential difference between the sand we used and sediments reported in the Columbia River was the amount of organic content. Jolley and others (2014) reported 0.9-8.4 percent organic content in sediments collected in the lower Columbia River, whereas our sand had no organic content. If these experiments had used a sediment type that allowed fish to re-burrow following exposure to dewatering, fish may have emerged from the sediment at a different rate, or shown different movement or survival patterns. The use of a 48-h post-exposure holding period was informative, as some mortality was delayed. Most of the delayed mortality was expressed during the first $24 \mathrm{~h}$ of post-exposure holding, with a few additional mortalities occurring up to $48 \mathrm{~h}$. The holding period also allowed us to observe how quickly fish were able to recover following exposure to dewatering, and the ultimate fate of fish that we classified as lethargic at the time of sampling. The hardiness of these fish was evident when fish that had been exposed to dewatered conditions for 24 or $36 \mathrm{~h}$ were removed from the surface of a sampling tube and placed in water. They typically were completely covered in sand and appeared shriveled and desiccated, often to the point where it was not clear whether they were alive or dead. But, when they were placed in water, they very quickly began swimming and were very active. Some fish (about 10 percent) were not immediately active when placed in water and were classified as lethargic. Most of the lethargic fish were alive and swimming at the end of the 48-h holding period (63 percent), 29 percent died in the first $24 \mathrm{~h}$ of holding, and 8 percent were still lethargic after $48 \mathrm{~h}$. Although a 24-h holding period would have captured most of the delayed mortality, we recommend the use of a 48-h holding period for future studies. Finally, the need to remove ammocoetes from sediments proved to be challenging and resulted in changes to our procedures in an effort to reduce the risk of fish injury. 
During the movement trials, we removed fish from the test tank using a scoop. We noted some minor injuries to fish that appeared to be from the scoop. The injuries were incurred after the trials were complete (during the fish recovery), so they did not influence the findings, but we decided to design an improved collection system for the survival trial. As the tubes used for the survival trials were fairly portable, they were lifted onto a cradle that positioned the tube so that the contents could be readily washed out into a collection tray. We then used a light spray to wet the sediment and to create a slurry that poured into the tray. This system was gentle to fish, and we are confident that our efforts to recover them from the sample tubes did not affect their survival.

Future research on ammocoete responses to dewatering should include testing with different sediment types, a wider range of environmental conditions, and the influence of repeated exposures. A range of sediment types, with properties that vary under dewatered conditions, should be tested. More information is needed on which sediment types are selected by ammocoetes in the Columbia River and which types they prefer, as compared to which types they will use when choices are limited. The range of air temperature and humidity conditions tested during the survival trials was limited, as this was the first research on this topic. Temperature influences ammocoete survival (Meeuwig and others, 2005); therefore, inferences based on the reported mortality at each exposure period should be limited to air temperatures between 13 and $17^{\circ} \mathrm{C}$. We would expect mortality to be higher for lamprey dewatered on Columbia River or tributary shorelines in July or August when air temperatures reach or exceed $30{ }^{\circ} \mathrm{C}$. Additionally, our tests were conducted during the day, and future tests should include some night testing to see if responses differ (Bracken and Lucas, 2013; Moser and others, 2015). Finally, future research should include trials where individual fish are exposed to dewatering conditions numerous times, representing a more realistic scenario for shorelines in the Columbia River. This initial experimental work used only naïve fish, whose first exposure to dewatering was their only exposure. Furthermore, we would recommend that test fish be captured from a field location and acclimated to laboratory conditions for a short period. The lamprey used for this work had been in culture in our laboratory for many years. They could represent the equivalent of hatchery-reared juvenile salmon in that their responses to test conditions may not accurately reflect responses of fish only exposed to natural settings. Expanding this initial laboratory work to create direct linkages with realistic ammocoete and environmental conditions from Columbia River settings would provide managers the best possible information to protect lamprey during hydropower system operations.

\section{Acknowledgments}

This work was funded by the U.S. Army Corps of Engineers, Portland District, under MIPR \#W66QKZ40319245. Sean Tackley, U.S. Army Corps of Engineers, was the contract manager and provided meaningful contributions to the study design. Lampreys were provided by Yakama Nation Fisheries, the Confederated Tribes of Warm Springs, and Oregon Department of Fish and Wildlife. Colleagues at the U.S. Geological Survey (USGS) Columbia River Research Laboratory (CRRL) provided assistance with experimental setup and execution, and we gratefully acknowledge Dennis Sitherwood, Joe Warren, Ryan Tomka, William Hurst, Lisa Gee, and Toby Kock. Hal Hansel, also of CRRL, assisted with the logistic regression analysis. Reviews of the document by Ralph Lampman, Yakama Nation, and Brady Allen, USGS, were greatly appreciated. 


\section{References Cited}

Braken, F.S.A., and Lucas, M.C., 2013, Potential impacts of small-scale hydroelectric power generation on downstream moving lampreys: River Research and Applications, v. 29, p. 1073-1081.

Close, D.A., Fitzpatrick, M., and Li, H., 2002, The ecological and cultural importance of a species at risk of extinction, Pacific lamprey: Fisheries, v. 27, p. 19-25.

Jolley, J.C., Silver, G.S., Skalicky, J.J., and Whitesel, T.A., 2014, Evaluation of larval Pacific lamprey rearing in mainstem areas of the Columbia and Snake Rivers impacted by dams: Annual report prepared by U.S. Fish and Wildlife Service, Columbia River Fisheries Program Office, Vancouver, Washington.

Jolley, J.C., Silver, G.S., and Whitesel, T.A., 2012, Occupancy and detection of larval Pacific lampreys and Lampetra spp. in a large river-The lower Willamette River: Transactions of the American Fisheries Society, v. 141, p. 305-312.

Jolley, J.C., Silver, G.S., and Whitesel, T.A., 2013, Occurrence, detection, and habitat use of larval lamprey in Columbia River mainstem environments: The Dalles Pool and Deschutes River Mouth: Annual report prepared by U.S. Fish and Wildlife Service, Columbia River Fisheries Program Office, Vancouver, Washington.

Lawrence, M.G., 2005, The relationship between relative humidity and the dewpoint temperature in moist air-Aa simple conversion and applications: Bulletin of the American Meteorological Society, v. 86 , p. 225-233.

Meeuwig, M.H., Bayer, J.M., and Seelye, J.G., 2005, Effects of temperature on survival and development of early life stage Pacific and Western brook lampreys: Transactions of the American Fisheries Society, v. 134, p. 19-27.

Moser, M.L., Jackson, A.D., Lucas, M.C., and Mueller, R.P., 2015, Behavior and potential threats to survival of migrating lamprey ammocoetes and macrophthalmia: Reviews in Fish Biology and Fisheries, v. 25, p.103-116.

Mueller, R.P., Rakowski, C.L., Perkins, W.A, and Richmond, M.C., 2014, Assessment of fluctuating reservoir elevations using hydraulic models and impacts on larval Pacific lamprey rearing habitat in the Bonneville pool: Draft Final Report PNNL-23876 submitted to the U.S. Army Corps of Engineers, Portland District, Portland, Oregon, by Pacific Northwest National Laboratory, Richland, Washington.

Rose, B.P., and Mesa, M.G., 2012, Effectiveness of common fish screen materials to protect lamprey ammocoetes: North American Journal of Fisheries Management, v. 32, p. 597-603. 
Publishing support provided by the U.S. Geological Survey

Science Publishing Network, Tacoma Publishing Service Center

For more information concerning the research in this report, contact the Director, Western Fisheries Research Center U.S. Geological Survey

6505 NE 65th Street

Seattle, Washington 98115

http://wfrc.usgs.gov/ 
